\title{
RESPONSE OF MONOCYTE-DERIVED DENDRITIC CELLS TO RAPIDLY SOLIDIFIED NICKEL-TITANIUM RIBBONS WITH SHAPE MEMORY PROPERTIES
}

\author{
S. Tomić1 ${ }^{2}$ R. Rudolf ${ }^{2,3}$, M. Brunčko ${ }^{2}$, I. Anžel ${ }^{2}$, V. Savićc ${ }^{4}$ and M. Čolić ${ }^{1,4 *}$ \\ ${ }^{1}$ Institute for Medical Research, Military Medical Academy, Belgrade, 11000, Serbia \\ ${ }^{2}$ Faculty of Mechanical Engineering, University of Maribor, 2000, Slovenia \\ ${ }^{3}$ Zlatarna Celje d.d., Celje, 3000, Slovenia \\ ${ }^{4}$ Faculty of Medicine, University of Niš, 18000 Serbia
}

\begin{abstract}
Ni-Ti Shape Memory Alloys (SMAs) have attracted considerable attention as biomaterials for medical devices. However, the biocompatibility of Ni-Ti SMAs is often unsatisfactory due to their poor surface structure. Here we prepared Rapidly Solidified (RS) Ni-Ti SMA ribbons by melt-spinning and their surface was characterised by Augerelectron spectroscopy, X-ray photoelectron spectrometry and scanning electron microscopy. The biocompatibility of the produced ribbons and their immunomodulatory properties were studied on human monocyte-derived dendritic cells (MoDCs). We showed that melt-spinning of Ni-Ti SMAs can form a thin homogenous oxide layer, which improves their corrosion resistance and subsequent toxicity to MoDCs. Ni-Ti RS ribbons stimulated the maturation of MoDCs, as detected by changes in the cells' morphology and increased expression of HLA-DR, CD86, CD40 and CD83 molecules. However, Ni-Ti RS ribbons enhanced the tolerogenic properties of immature MoDCs, which produced higher levels of IL-10 and IL-27, driving the differentiation of IL- 10 - and TGF- $\beta$-producing CD4 ${ }^{+} \mathrm{T}$ cells. On the other hand, in the presence of lipopolysaccharide, an important pro-inflammatory biomolecule, Ni-Ti RS ribbons enhanced the allostimulatory and Th1 polarising capacity of MoDCs, whereas the production of Th2 and Th17 cytokines was down-regulated. In conclusion, NiTi RS ribbons possess substantial immunomodulatory properties on MoDCs. These findings might be clinically relevant, because implanted Ni-Ti SMA devices can induce both desired and adverse effects on the immune system, depending on the microenvironmental stimuli.
\end{abstract}

Keywords: Nickel-titanium alloy, biocompatibility, cytokines, immunomodulation, monocyte-derived dendritic cells.

*Address for correspondence:

Miodrag Čolić

Military Medical Academy

Crnotravska 17

11000 Belgrade, Serbia

Telephone/FAX Number: +381112662722

E-mail: fakultet.vma@mod.gov.rs

\section{Introduction}

From their discovery in 1965 (Buehler and Wang, 1968) to the present day, the exciting properties of Shape Memory Alloys (SMAs) have preoccupied the interest of many investigators trying to understand, apply or improve these extraordinary "smart materials". The most frequently manufactured Ni-Ti SMAs are able to sense the changes in thermal and mechanical stimuli and respond through a complex thermoelastic reversible phase (martensite-austenite) transformation. This results in the remarkable properties of SMAs, such as shape memory effects and super elasticity. Ni-Ti SMAs also possess excellent fatigue resistance and a high damping capacity. These properties makes Ni-Ti SMAs an attractive tool for various types of biomedical devices (stents, actuators, filters, shape memory staples, inter-body fusion devices, endoprostheses etc.) (Hoh et al., 2009).

Because of the high Ni content $(50.8$ at $\%$ in devices transformable at physiological temperatures) enthusiasm for the use of Ni-Ti based SMAs in biomedical engineering has been tempered by concern regarding its biocompatibility (Shabalovskaya, 2002). In contrast to pure Ni, which is known to induce carcinogenicity and toxicity of a wide spectra of living tissues (Das et al., 2008), Ni-Ti SMAs demonstrated rather good biocompatibility (Shabalovskaya, 2002). This is because $\mathrm{Ti}$ is more readily oxidised than $\mathrm{Ni}$, so the biologically inert Ti-oxide layer and extracellularderived calcium-phosphate layer on the Ni-Ti surface prevent the release of Ni (Es-Souni and Fischer-Brandies, 2005). However, since Ti-oxide is a very brittle ceramic, it can be damaged during dynamic mechanical loading (Peitsch et al., 2007) or under inflammatory conditions (Messer et al., 2009), leading inevitably to the initiation of corrosion and increased release of $\mathrm{Ni}$ ions, causing local or systematic adverse health effects (Das et al., 2008). This could lead to necrotic and apoptotic changes of the tissue surrounding the implant (Bogdanski et al., 2004), increased expression of inflammatory mediators such as tumour necrosis factor-alpha (TNF- $\alpha$ ) and interleukin 6 (IL-6) and reduced proliferation of cells near the implant (Es-Souni and Fischer-Brandies, 2007). These studies indicate the necessity for developing strategies for improvement of corrosion resistance of $\mathrm{Ni}-\mathrm{Ti}$ based alloys and prevention of $\mathrm{Ni}$ release from the alloy.

A variety of methods have been attempted to improve the mechanical properties of SMAs by producing finergrained Ni-Ti alloys. Rapid Solidification (RS) is one such technique that enables the production of ribbon-shaped small-sized devices with improved ductility, transformation temperatures and hysteresis of Ni-Ti alloys (Santamarta 
et al., 2004). Earlier, our group described how the wheel speed (solidification rate) influences the microstructure and enhances the shape memory characteristics of Ni-Ti ribbons (Mehrabi et al., 2009). Many properties of melt-spun Ni-Ti ribbons, including their microstructures, depend strongly on the processing parameters (Kramer et al., 2007), so the characterisation of the material and its biocompatibility are needed for each new set of parameters.

In our latest study (Rudolf et al., 2010) we showed that Ni-Ti RS ribbons were not cytotoxic for human peripheral blood mononuclear cells after $48 \mathrm{~h}$ exposure in culture. However, we found that the cells of some donors responded to Ni-Ti RS ribbons by increasing the production of IL-10, whereas no initiation of the production of pro-inflammatory cytokines was observed. Since IL-10 is a very important cytokine for self-limiting Th1 cell-mediated immunopathology in conditions of strong inflammatory stimuli (Saraiva and O'Garra, 2010), these exciting findings suggest that $\mathrm{Ni}$-Ti RS ribbons may possess tolerogenic properties intrinsically, which could launch their wide clinical application quickly. The functional response of peripheral blood mononuclear cells (PB-MNCs) in our culture model depends strongly on accessory, antigen-presenting cells (APCs), among which dendritic cells (DCs) play a key role. So we hypothesise that DCs are the primary target of the tolerogenic effect of RS Ni-Ti ribbons. DCs are the most potent APCs, orchestrating and fine-tuning the whole immune response depending on the environmental stimuli (Banchereau et al., 2000), including biomaterials (Rogers and Babensee, 2011). In steady state conditions, DCs are in an immature or semi-mature state and possess profound tolerogenic properties, which enable them to induce and support peripheral tolerance to self antigens (Steinman et al., 2003). However, upon encountering dangerous signals, such as damage- or pathogens-associated molecular patterns, including lipopolysaccharide (LPS) (Sallusto and Lanzavecchia, 1994), and pro-inflammatory cytokines (Bender et al., 1996), DCs mature by expressing high levels of Major Histocompatibility Complex (MHC) (Inaba et al., 2000), co-stimulatory molecules (Inaba et al., 1994) and CD83, a marker of DCs maturation (Tze et al., 2011). Simultaneously, DCs migrate to the peripheral lymph nodes, activate naïve T cells (Steinman et al., 1993) and direct their differentiation towards $\mathrm{T}$ helper (Th)1, Th2 (Constant and Bottomly, 1997), Th17 (McGeachy and Cua, 2008), or T regulatory (Vignali et al., 2008) subsets. The differentiation of Th cells into these subsets is mediated by specific cytokines produced by DCs such as IL-12 (Trinchieri, 2003), IL-23, IL-27 (Hunter, 2005) and IL-10 (Steinman et al., 2003), as well as co-stimulatory molecules (Banchereau et al., 2000), all of which leads to an appropriate immune response. The importance of Th17 cells has just recently been recognised in clearing pathogens during host defence reactions, but also in inducing tissue inflammation in autoimmune diseases (McGeachy and Cua, 2008).

The key mechanisms by which Ni induces allergic reactions include the sensitisation of a subset of skin DCs (Langerhans' cells) by Ni-protein complexes and activation of effectors and memory T cells (Moulon et al., 1995).
Whether similar mechanisms are involved in the local immune response to $\mathrm{Ni}-\mathrm{Ti}$ implants is unknown currently. Therefore, the aim of our study was to investigate the cytotoxicity of Ni-Ti RS ribbons using a model of human monocyte derived (Mo)DCs and the functional response of MoDCs to such SMA samples in terms of their phenotypic changes, cytokines production, allostimulatory and Th polarisation capacity under normal and inflammatory conditions. These biological effects were correlated with the surface composition and microstructure of RS Ni-Ti ribbons, including characterisation of the oxide layer, and changes occurred at the alloy surface after conditioning of the ribbons in cell culture medium.

\section{Materials and Methods}

\section{Preparation of Ni-Ti RS ribbons and control Ni-Ti plates}

In our previous paper we described in detail the preparation of RS SMAs ribbons (Lojen et al., 2005) including Ni-Ti RS ribbons (Rudolf et al., 2010). Briefly, Ni-Ti (with 50.3 $\% \mathrm{Ti}$ ) ingots were prepared by the vacuum arc-melting technique on a water-cooled copper hearth in a reduced Ar atmosphere. To ensure homogeneous bulk SMAs, arcmelting was repeated three times for each alloy. The meltspun ribbons were produced by re-melting bulk Ni-Ti and the process was undertaken in a 200 mbar He atmosphere in a quartz-glass crucible with a nozzle diameter of $0.9 \mathrm{~mm}$. Because of melt stickiness problems, the crucible was coated internally with $\mathrm{Y}_{2} \mathrm{O}_{3}$ in order to increase resistance of the crucible to aggressive chemical attack at high temperatures when handling the most highly-reactive molten materials, including Ti. By applying an Ar overpressure of 90 mbar within the crucible, the melt was ejected onto the surface of a polished $\mathrm{Cu}$ wheel $(200 \mathrm{~mm}$ in diameter) having a circumferential wheel speed of $15 \mathrm{~ms}^{-1}$. The distance between the nozzle and the wheel surface was $2 \mathrm{~mm}$. NiTi RS ribbons were prepared as $5 \mathrm{~mm}$ x $5 \mathrm{~mm}$ x $0.1 \mathrm{~mm}$ plates and analysed by Scanning Electron Microscopy (SEM)/ Energy Dispersive X-ray (EDX) (Sirion 400 NC, FEI, Hillsboro, OR, USA) after cleaning in an ultrasonic bath (Fig. 1).

Control Ni-Ti plates were prepared from the same $\mathrm{Ni}-\mathrm{Ti}$ ingots as Ni-Ti RS ribbons after cutting the material into plates $5 \mathrm{~mm}$ x $5 \mathrm{~mm}$ x $1 \mathrm{~mm}$ using electro-erosion. After that, SEM/EDX analysis was performed and revealed the rough surface of the plates, which was contaminated with elements such as $\mathrm{Cu}, \mathrm{Zn}$ and $\mathrm{C}$. Therefore, the native bulk Ni-Ti samples were ground on Silicon Carbide paper from 80 to a final mesh size of 4,000 and then polished with $3 \mu \mathrm{m}$ and 1 $\mu \mathrm{m}$ C-suspensions. SEM/ EDX analysis was performed after cleaning the polished samples in an ultrasonic bath (Fig. 1). Since the analysis showed no detectable contaminants, these plates were used as control Ni-Ti plates in the cytotoxicity tests.

\section{Microstructure analysis of the surface of Ni-Ti RS ribbons}

The surface of Ni-Ti RS ribbons was analysed before and after the conditioning in cell culture media for 2 
Native bulk Ni-Ti plate
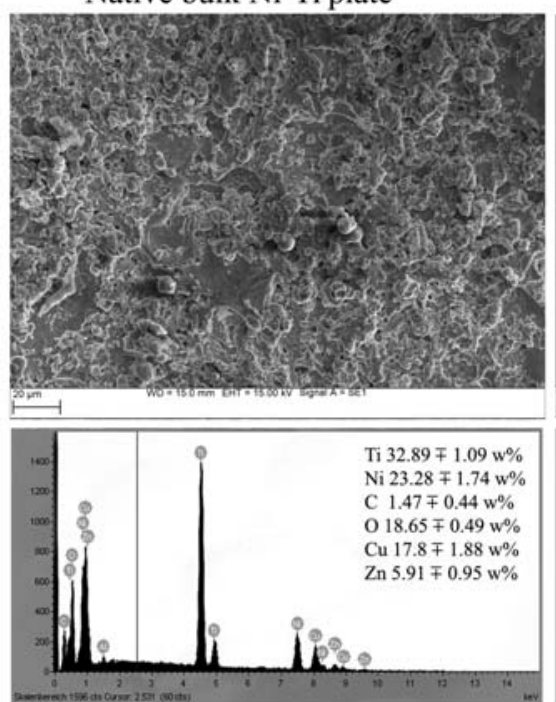

Control Ni-Ti plate

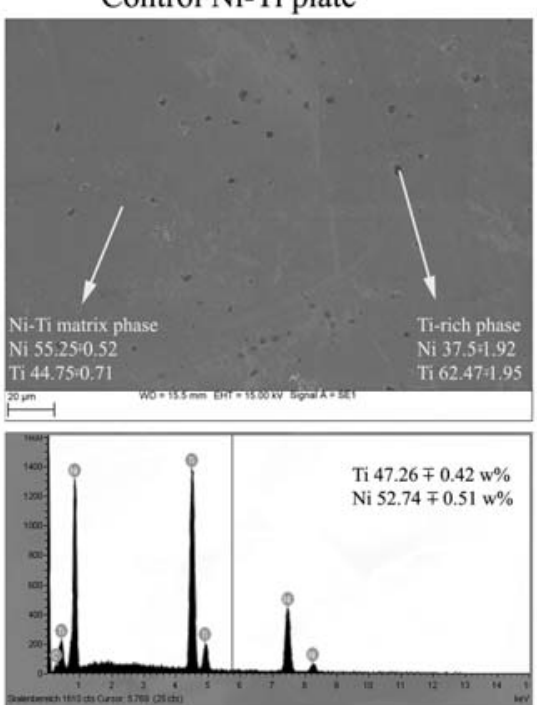

Ni-Ti RS ribbon

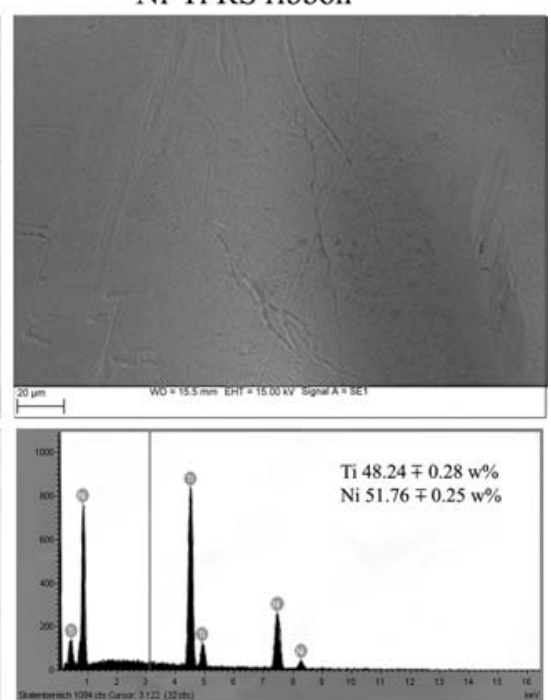

Fig. 1. SEM/EDX analysis of Ni-Ti samples. Ni-Ti samples were prepared as described in Materials and Methods. Representative EDX analyses of each Ni-Ti sample are shown below the images. The numbers on the EDX spectra represent mean weight (w) $\% \pm \mathrm{SD}$ obtained by the EDX analyses taken from 8 areas $50 \times 50 \mu \mathrm{m}^{2}$ in size. The two detected intermetallic phases on the control Ni-Ti plates were identified using spot EDX analysis (values are given as mean $\mathrm{w} \% \pm \mathrm{SD}, n=9)$.

days. SEM, Auger-Electron Spectroscopy (AES) and $\mathrm{X}$-ray Photoelectron Spectrometry (XPS) were used to characterise the surface of Ni-Ti RS ribbons by using VG-Scientific Microlab 310F SEM/AES/XPS. A primary electron beam was at a current of $10 \mathrm{nA}$ and kinetic energy of $10 \mathrm{keV}$, giving a resolution of $10 \mathrm{~nm}$. For XPS and AES analysis, the samples were cleaned with $\mathrm{Ar}^{+}$ions $(\mathrm{E}=2 \mathrm{keV}$, $\mathrm{r}=12 \mathrm{mAc} \mathrm{m}^{-2}, \mathrm{Q}=47$ ) to remove surface contaminants. For all XPS measurements $\mathrm{Mg} \mathrm{K} \alpha$ radiation at $1486.6 \mathrm{eV}$ with anode voltage $\times$ emission current $=12.5 \mathrm{kV} \times 16 \mathrm{~mA}$ $=200 \mathrm{~W}$ power was used. The XPS analysis was performed after the sample was sputtered with $\mathrm{Ar}^{+} 3 \mathrm{keV}$ for $5 \mathrm{~min}$. For AES depth profiles, the samples were sputtered with a $3 \mathrm{keV} \mathrm{Ar}^{+}$sputter rate of about $1.2 \mathrm{~nm} / \mathrm{min}$ and the analysis was performed before the first sputtering and after each sputter cycle. The sputtering rate was estimated based on the average sputtering rate calculated from a $\mathrm{SiO}_{2}$ reference under similar conditions (Shabalovskaya and Anderegg, 1995).

\section{Preparation of Ni-Ti samples for biocompatibility and conditioning studies}

Ni-Ti RS ribbons and control Ni-Ti plates were used for the biocompatibility and conditioning studies. In conditioning experiments we also used pure $\mathrm{Ni}$ and $\mathrm{Ti}$ plates as positive controls, to evaluate the leaching of $\mathrm{Ti}$ and $\mathrm{Ni}$ ions. These plates were of the same size as the control Ni-Ti plates.

All the metal/alloy samples were washed in distilled water and cleaned with an ultrasonic apparatus (5 x 3 min in distilled water). After that, the samples were air dried for $1 \mathrm{~h}$ and then disinfected in $96 \%$ alcohol for 5 min. After drying, the ribbons and plates were placed in 24-well plates (6-plicates of each sample) (Costar Sigma, Munich, Germany) containing cell culture medium. The culture medium was complete RPMI 1640 medium
(Sigma, Munich, Germany) supplemented with $2 \mathrm{mM}$ L-glutamine, $20 \mu \mathrm{g} / \mathrm{mL}$ gentamicin, $100 \mathrm{U} / \mathrm{mL}$ penicillin, $100 \mathrm{mg} / \mathrm{mL}$ streptomycin (ICN, Costa Mesa, CA, USA), $50 \mu \mathrm{mol} 2$-mercaptoethanol (2-ME) (Sigma), $10 \%$ heat inactivated foetal calf serum (FCS; PAA Laboratories Vienna, Austria) (Fischer, 1975; Bannai, 1992). The metal/ alloy samples were incubated (conditioned) in the medium for 2 days following the ISO recommendations for the biocompatibility testing of medical and dental materials (International Standards Organisation, 2009). The samples' surface area exposure to the medium was $2 \mathrm{~cm}^{2} \mathrm{ml}^{-1}$. The control conditioning medium without the metallic samples was used as a blank control.

After conditioning, media were collected, centrifuged and used for the determination of metal ion release by Inductively Coupled Plasma Atomic Emission Spectroscopy (ICP-AES). Triplicate absorbance readings per element were recorded for each sample.

\section{Preparation of cell cultures}

MoDCs were generated from PB-MNCs, as described previously (Colic et al., 2003). Briefly, PB-MNCs were obtained from the buffy coats of healthy volunteers upon obtaining a signed informed consent. The cells were isolated by density-gradient centrifugation (Lymphoprep, PAA) and then resuspended in culture medium to allow their adherence to 6 -well plates at $37{ }^{\circ} \mathrm{C}$. After that, the non-adherent cells were removed and the adherent cells, predominantly monocytes, were cultivated in $2 \mathrm{~mL}$ of DC differentiation medium for 5 days. The culture medium for the generation of human MoDCs consisted of the complete RPMI medium supplemented with $100 \mathrm{ng} / \mathrm{mL}$ of the human recombinant granulocyte macrophage colony stimulating factor (GM-CSF, Leucomax, Basel, Switzerland) and 20 $\mathrm{ng} / \mathrm{mL}$ of the human recombinant IL-4 (Roche Diagnostics, 
Mannheim, Germany). On day 5, immature MoDCs were transferred to 24 well-plates $\left(1 \times 10^{5}\right.$ cells/well $/ \mathrm{mL}$ of medium) which already contained pre-sterilised $\mathrm{Ni}$-Ti RS ribbons or control Ni-Ti plates at the size/volume ratio as indicated above. Control cultures included the cultivation of MoDCs on plastic, polystyrene cover slips $8 \mathrm{~mm}$ in diameter. MoDCs were then cultivated for 2 or 5 days in an incubator with $5 \% \mathrm{CO}_{2}$. In the MoDC maturation experiments LPS (Sigma), at a concentration of $0.5 \mu \mathrm{g} / \mathrm{mL}$, was added to the control and $\mathrm{Ni}$-Ti RS ribbons-containing MoDC cultures, following the cultivation of the cells for 2 days.

\section{Cytotoxicity study}

After the two-day or five-day cultures, the viability of MoDCs was determined with a $1 \%$ solution of Trypan blue. Non-viable cells, stained with Trypan blue, were determined by light microscopy and the percentage of viable cells was determined from the total cell count. The comparable results were obtained additionally by staining the cells with propidium iodide (PI) $(10 \mu \mathrm{g} / \mathrm{mL}$; Sigma). The percentage of stained, necrotic cells was determined by using a flow cytometer (EPICS XL-MCL; Coulter, Krefeld, Germany). Apoptosis was determined by staining the cells with PI (10 $\mu \mathrm{g} / \mathrm{mL}$ dissolved in a permeabilisation buffer - hypotonic citric acid + Triton X-100 buffer), as described above. After $6 \mathrm{~h}$ incubation at room temperature in the dark, the cells were analysed and those with hypodiploid nuclei (sub- $\mathrm{G}_{0}$ ) were considered apoptotic cells. The experiments were repeated four times and each was carried out in sixplicates. To confirm the results obtained from PI staining, the cells were labelled additionally with Annexin-V-Fitc/PI according to the manufacturer's instructions for the kit (R\&D Systems, Minneapolis, MN, USA). The test enabled identification of early apoptotic (Annexin-V-FITC ${ }^{+} / \mathrm{PI}^{-}$) cells, late apoptotic/ secondary necrotic (Annexin-V-FITC ${ }^{+} / \mathrm{PI}^{+}$) cells, and primary necrotic (Annexin-V-FiITC $-/ \mathrm{PI}^{+}$) cells. The experiment was carried out once in sixplicates.

\section{Scanning electron microscopy analysis of MoDCs}

After the culture the medium was removed and the samples of immature or LPS-matured MoDCs cultivated on plastic cover slips, Ni-Ti RS ribbons or control Ni-Ti plates were fixed overnight at $+4{ }^{\circ} \mathrm{C}$ in a $2 \%$ glutaraldehyde/Millonig buffer. The samples were then washed 3 times in Millonig buffer, for $10 \mathrm{~min}$ each time, and post-fixed in $1 \%$ osmiumtetroxide in distilled water for $1 \mathrm{~h}$. All these chemicals were obtained from Sigma. The samples were then washed three times in water and dehydrated in an increasing series of ethanol (30\% - $100 \%)$ solutions, for 5 min each time. After that, the samples were critical point dried and placed on carbon adhesive tape on aluminium sample holders. Gold sputtering was performed (JFS-1100E) at $10 \mathrm{~mA}$ for $4 \mathrm{~min}$ and the samples were analysed on an SEM JSM5300 (Jeol, Tokyo, Japan) at 10-30 kV primary beam.

\section{Flow cytometry}

After two days of cultivation of MoDCs with Ni-Ti RS ribbons, the expression of key surface markers of immature and LPS-treated MoDCs was evaluated by flow cytometry. The following monoclonal antibodies (mAbs) were used:
CD86-phycoerithryne (PE), anti-HLA-DR-PE, mouse IgG1a negative control - fluorescein isocyanate (FITC) and mouse IgG1a negative control - PE (all from Serotec, Oxford, UK); anti-CD40- FITC and anti-CD83-FITC (Imunotools, Friesoythe, Germany). The cells were collected and washed once in a phosphate buffer solution (PBS) containing $2 \%$ FCS and $0.1 \%$ sodium azide. The cells were then incubated with primary mAbs labelled directly for $1 \mathrm{~h}$ at $4{ }^{\circ} \mathrm{C}$, using the concentrations recommended by the manufacturer. The cells were than washed by centrifugation and analysed by flow cytometry. The cells were gated according to the cellspecific forward scatter/ side scatter (FS/SS) parameters. Before each analysis, signal compensation was performed for each pair of mAbs used in double-staining procedures, and the specific fluorescence was determined based on the single labelled controls.

\section{Allogenic mixed leukocyte reaction}

To assess the allostimulatory capacity of MoDCs cultivated with Ni-Ti RS ribbons, the cells were detached from the ribbons or control coverslips by pipetting. After that, MoDCs were washed in complete culture medium and used in the allogenic mixed leukocyte reactions (MLRs). $\mathrm{CD} 4^{+} \mathrm{T}$ cells, used as responders, were purified from PBMNCs using a $\mathrm{CD}^{+} \mathrm{T}$ cell isolation kit (MACS technology, Miltenyl Biotech, Cologne, Germany), following the manufacturer's instructions. The purity of $\mathrm{CD}^{+} \mathrm{T}$ cells recovered in the negative fraction was usually higher than $95 \%$, as evaluated by anti-CD4 FITC (Serotec) staining and flow cytometry. The purified CD $4^{+} \mathrm{T}$ cells $\left(1 \times 10^{5}\right.$ cells/ well) were co-cultured in direct contact with immature or LPS-treated MoDCs $\left(1 \times 10^{4}, 0.5 \times 10^{4}\right.$ or $0.25 \times 10^{4}$ cells/ well) in 96-well plates giving different $\mathrm{MoDC} / \mathrm{CD}^{+} \mathrm{T}$ cell ratios (1:10, 1:20 and 1:40, respectively) in complete RPMI medium. Additional controls were $\mathrm{CD}^{+} \mathrm{T}$ cells or MoDCs, cultivated alone. After 5 days of MLR, the cells were pulsed with $\left[{ }^{3} \mathrm{H}\right]$-thymidine for the last $18 \mathrm{~h}(1$ $\mu \mathrm{Ci}$ /well, Amersham, Bucks, UK) in order to assess their incorporation into DNA. The labelled cells were harvested onto glass fibre filters and the radioactivity was counted in a Beckman scintillation counter and expressed as counts per minute $(\mathrm{cpm}) \pm \mathrm{SD}$ of sixplicates.

To determine the Thelper (Th) cytokine profiles, $\mathrm{CD}^{+}$ cells were cultivated as in the proliferation assay. After the MLR, PMA 20 ng/mL (Sigma) and ionomycin 500 ng/mL (Merck, Vienna, Austria) were added to the co-cultures for the last $18 \mathrm{~h}$ to enhance the release of cytokines, after which supernatants were collected and frozen at $-40{ }^{\circ} \mathrm{C}$ until the analysis. The levels of cytokines were determined in those co-cultures where the MoDC/CD4 ${ }^{+} \mathrm{T}$ cell ratio was 1:40. Additional controls were those as described above.

\section{Detection of cytokines}

The levels of IL-10, IL-12, IL-23 and IL-27 were determined in cell-free supernatants of MoDCs cultures using sandwich ELISA kits (R\&D Systems), following the manufacturer's instructions. Levels of IL-1 $\beta$, Interferon (IFN)- $\gamma$, IL-4, IL-6, IL-8, IL-10, TNF- $\alpha$ and TNF- $\beta$ were determined in $\mathrm{CD}^{+} \mathrm{T} / \mathrm{MoDCs}$ co-culture supernatants using multiplex immunobead assay and flow cytometry (Flow Cytomix Human Th1/Th2 11plex Kit, Bender 
MedSystems, Vienna, Austria). The levels of IL-17 and transforming growth factor (TGF)- $\beta$ in these co-culture supernatants were determined by sandwich ELISA kits (R\&D Systems).

\section{Statistical analysis}

The results are presented as the mean \pm standard deviation (SD) of four independent experiments, if not indicated otherwise. The Wilcoxon matched pairs test (non-parametric test) was used to evaluate the differences between the experimental (Ni-Ti RS ribbons) and corresponding control samples (Control). In cytotoxicity experiments, the three experimental groups (Control, Ni-Ti RS ribbons and $\mathrm{Ni}$ - Ti plates) were compared using the Kruskal-Wallis test with Dunnett post-test. Statistical analysis of the differences obtained in the proliferation assays were performed using one-way ANOVA with a Dunnett post-test, because the data within each experiment followed the Gaussian distribution according to the Kolmogorov-Smirov test (with DallalWilkinson-Lillefor P value). Values at $p<0.05$ or less were considered significant statistically. All statistical analysis was performed in GraphPad (La Jolla, CA, USA) Prism 5 software.

\section{Results}

\section{Cytotoxicity of Ni-Ti RS ribbons and control bulk Ni-Ti plates on MoDCs}

In our previous paper we evaluated the cytotoxicity and immunomodulatory properties of $\mathrm{Ni}$-Ti RS ribbons using human PB-MNCs. The effects of Ni-Ti RS ribbons were studied in comparison with control Ni-Ti plates which were shown to be highly cytotoxic for PB-MNCs (Rudolf et al., 2010). To investigate further the mechanisms of the immunomodulatory properties of Ni-Ti RS ribbons, we first tested whether MoDCs respond to the Ni-Ti materials in a similar manner. As shown in Fig. 2, the number of MoDCs, their viability and the percentages of apoptotic and necrotic cells in cultures with $\mathrm{Ni}$-Ti RS ribbons, at both 2 day and 5 day cultures, was similar to that of control samples cultivated on plastic cover slips, confirming that Ni-Ti RS ribbons were not cytotoxic for MoDCs. In contrast, Ni-Ti control plates showed relatively high cytotoxicity, as judged by a significantly lower number of MoDCs after the cultures due to reduced viability of the cells by more than $60 \%$ (2 days) and $85 \%$ (5 days). Both types of cell death (necrosis and apoptosis) were involved in such an effect of control $\mathrm{Ni}$-Ti plates. The proportion of $\mathrm{Pi}^{+}$(necrotic) cells and $\mathrm{Pi}^{+} /$ Annexin- $\mathrm{V}^{+}$(late apoptotic, secondary necrotic) cells were higher than Annexin- $\mathrm{V}^{+}$(early apoptotic) cells, especially after 5 days of cultivation.

To check how these effects of Ni-Ti alloys correlated with their corrosion behaviour, ICP-AES analysis was performed to determine the amount of released $\mathrm{Ni}$ and $\mathrm{Ti}$ ions after conditioning of the samples in cell-free culture medium for $48 \mathrm{~h}$ (Table 1). As positive controls we also used pure Ni or Ti plates with corresponding surface per volume size. As expected, Ti ions have not been released significantly into the culture medium from a single tested sample. On the other hand, a significant release of $\mathrm{Ni}$ ions $(118.93 \mathrm{mg} / \mathrm{L})$ was detected in the conditioning medium of control Ni-Ti plates. The release of $\mathrm{Ni}$ ions was more than $50 \%$ lower than the release from the pure Ni plates $(281.92 \mathrm{mg} / \mathrm{L})$. In contrast, the concentrations of $\mathrm{Ni}$ ions in the conditioning medium of $\mathrm{Ni}$ - Ti RS ribbons was very close $(0.02 \mathrm{mg} / \mathrm{L})$ to the amount of $\mathrm{Ni}$ ions in the cell-free culture medium $(0.01 \mathrm{mg} / \mathrm{L})$. The corrosion properties of Ni-Ti samples were not modulated significantly in the presence of MoDCs (data not shown).

\section{SEM analysis of MoDCs cultivated on Ni-Ti samples} Morphological changes induced by the Ni-Ti samples were assessed by SEM analysis (Fig. 3). The surface characteristics of MoDCs were compared with those cultivated on control, plastic cover slips. The typical morphology of adherent immature MoDCs was found on plastic cover slips after $48 \mathrm{~h}$, including spindle-shaped morphology and the presence of microvilli. However, MoDCs cultivated on the Ni-Ti RS ribbons expressed more microvilli and veils were more prominent, suggesting that such cells are activated after contact with Ni-Ti RS ribbons. To confirm this hypothesis, immature MoDCs were grown on coverslips and activated with LPS for 2 days. As shown in Fig. 3, LPS-activated MoDCs also showed more prominent veils and microvilli compared to the control MoDCs, but the processes were more elongated compared to MoDCs cultivated on Ni-Ti RS ribbons. In contrast, the cells cultivated on Ni-Ti control plates possessed the characteristics of dead cells, mostly necrotic with the rounded shape and net-like morphology of the membrane.

Table 1. Ni and Ti release from Ni-Ti samples after 2 days of conditioning in cell-free culture medium.

\begin{tabular}{lll}
\hline Sample & Ti $(\mathbf{m g} / \mathbf{L})$ & Ni $(\mathbf{m g} / \mathbf{L})$ \\
Control medium & 0.02 & 0.01 \\
Ni plates & $n . d$. & 261.91 \\
Ti plates & 0.02 & $n . d$. \\
Control NiTi plates & 0.02 & 118.93 \\
NiTi RS ribbons & 0.02 & 0.02
\end{tabular}

n. d.- non-detectable. The results are presented as mean values (one experiment) calculated from triplicate absorbance readings per element. 


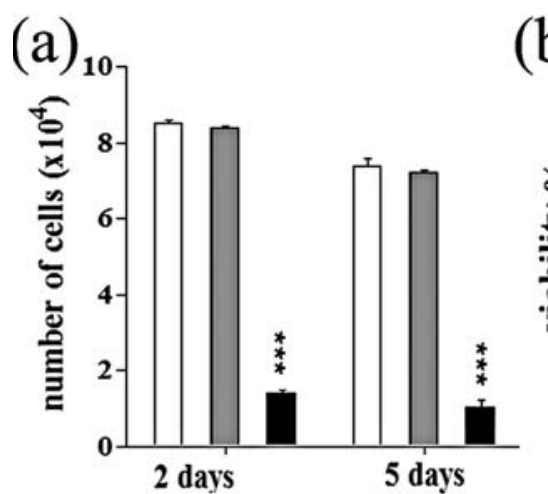

(d) (b)

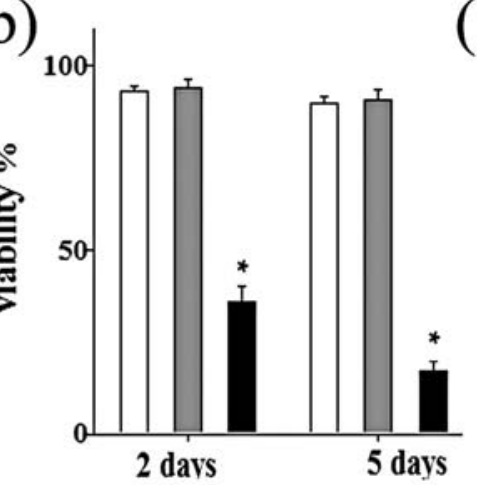

(c)

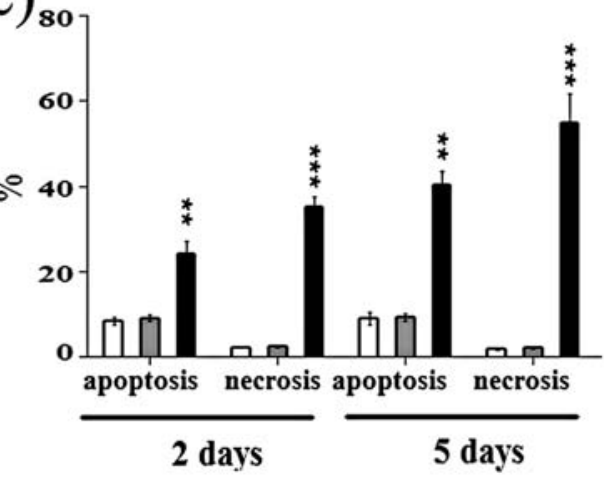

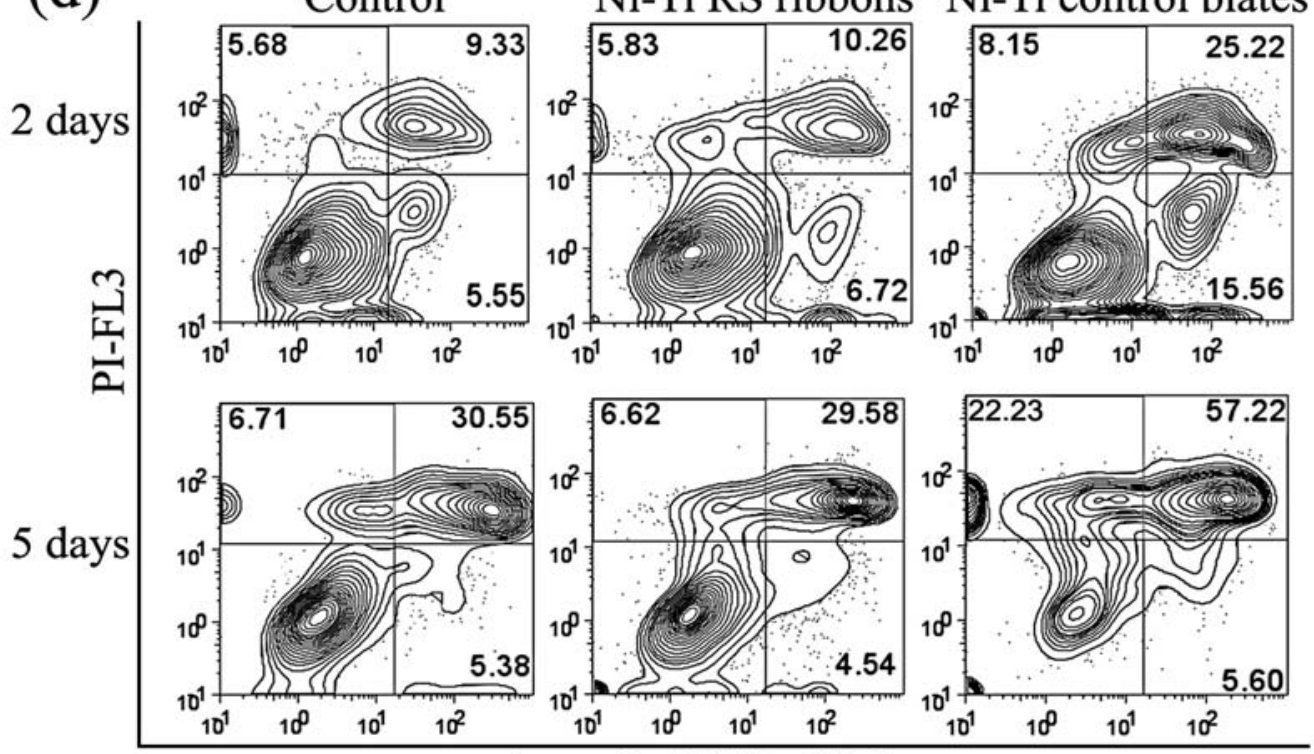

Annexin-V-Fitc- FL1

Fig. 2. The effect of Ni-Ti samples on the cytotoxicity of MoDCs after two or five days of exposure in cultures. (a) Number of cells; (b) Viability of cells; (c) Apoptosis and necrosis determined by PI staining; (d) Apoptosis and necrosis determined by Annexin-V-Fitc / PI double staining. White bars- control cells; Gray bars- MoDCs cultivated with Ni-Ti RS ribbons; Black bars-MoDCs cultivated with control Ni-Ti plates. The values represent mean $\pm \mathrm{SD}$ of four independent experiments, each carried out in sixplicates. ${ }^{*} p<0.05,{ }^{* *} p<0.01,{ }^{* * *} p<0.005$ compared to control cells (Kruskal-Wallis test).

\section{Phenotypical changes of MoDCs induced by Ni-Ti RS ribbons}

Activation of MoDCs observed by SEM at the Ni-Ti RS ribbons interface suggested that the cell-alloy interactions change the phenotypic properties of MoDCs. To confirm this hypothesis we analysed the expression of HLA-DR, CD86, CD83 and CD40. The results presented in Fig. 4 confirmed the immature phenotype of control MoDCs. The cultivation of MoDCs with Ni-Ti RS ribbons for 2 days showed up-regulation of all markers, indicating that Ni-Ti RS ribbons started to induce the maturation of MoDCs. Due to significant cytotoxicity, the MoDCs cultivated on control $\mathrm{Ni}$-Ti plates were not used for the later experiments.

\section{Functional properties of MoDCs cultivated with Ni- Ti RS ribbons}

Functional capabilities of MoDCs were assessed on the basis of their cytokine production, allostimulatory and Th polarisation properties. In supernatants of MoDCs cultures the levels of IL-10, IL-12, IL-23 and IL-27 were measured (Fig. 5a). We showed that Ni-Ti RS ribbons stimulated the production of IL-10 and IL-27 compared to control cultures without the ribbons. On the other hand, the production of IL-12 and IL-23 were not modified significantly.

The functional effects of MoDCs, previously cultivated for 2 days alone or in the presence of Ni-Ti RS ribbons, were tested in allogenic MLR using purified CD4 ${ }^{+} \mathrm{T}$ cells as responders. As shown in Fig. 5b, MoDCs cultivated with Ni-Ti RS ribbons had similar allostimulatory capacity as the control cells cultivated alone, in spite of the modified phenotype and changes in cytokine expression (see also Fig. 8).

However, when the levels of cytokines in supernatants of MoDC/CD4 co-cultures were analysed, different results were obtained (Fig. 5c). The level of TGF- $\beta$, IL-10 and IL-6 was significantly higher while the level of IL-8 and IL-17 was significantly lower in co-cultures with MoDCs experienced by $\mathrm{Ni}$-Ti ribbons in comparison with co-cultures 


\section{Control}

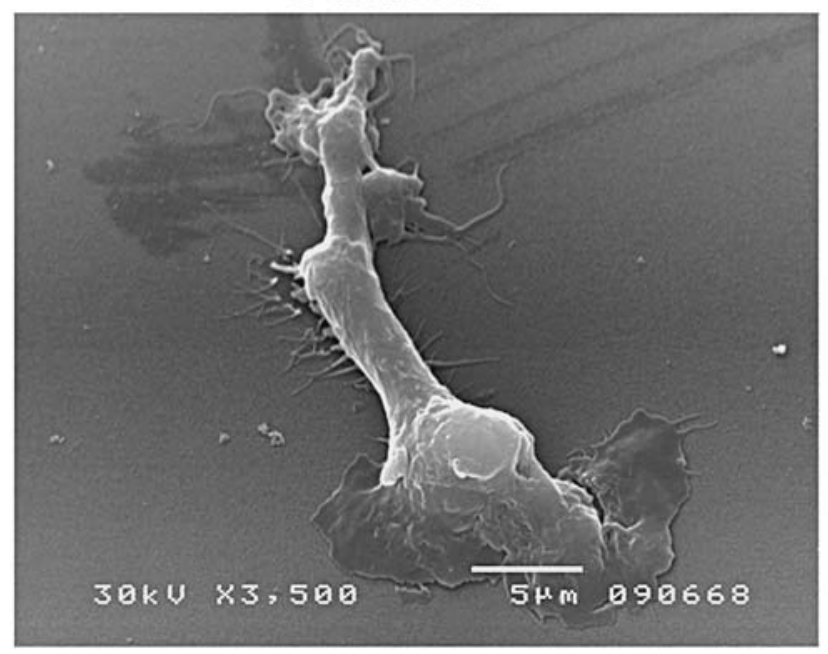

Ni-Ti RS ribbon

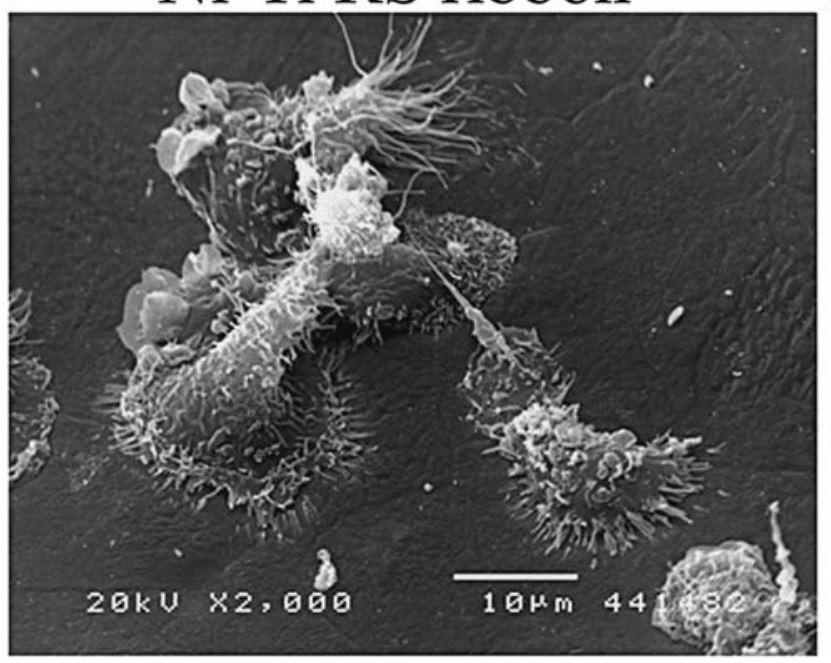

LPS

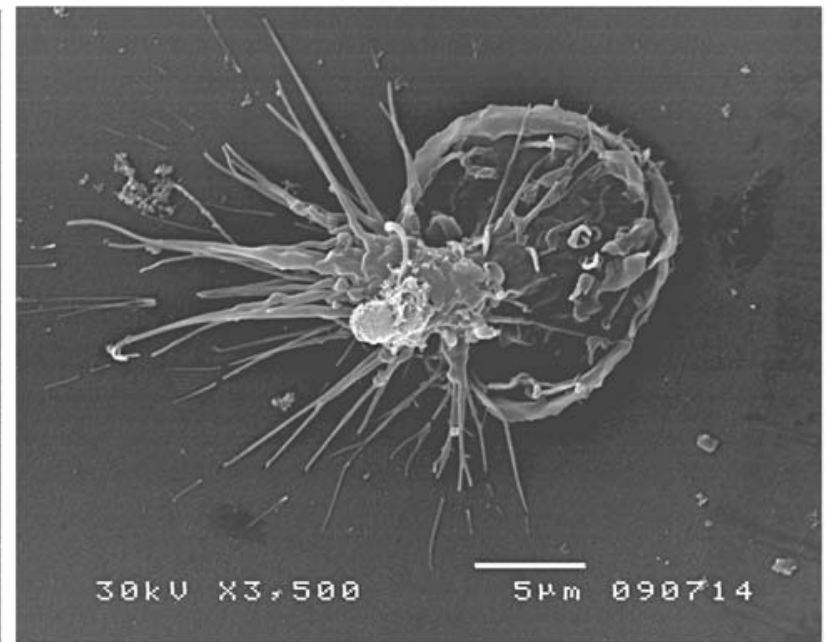

Control Ni-Ti plate

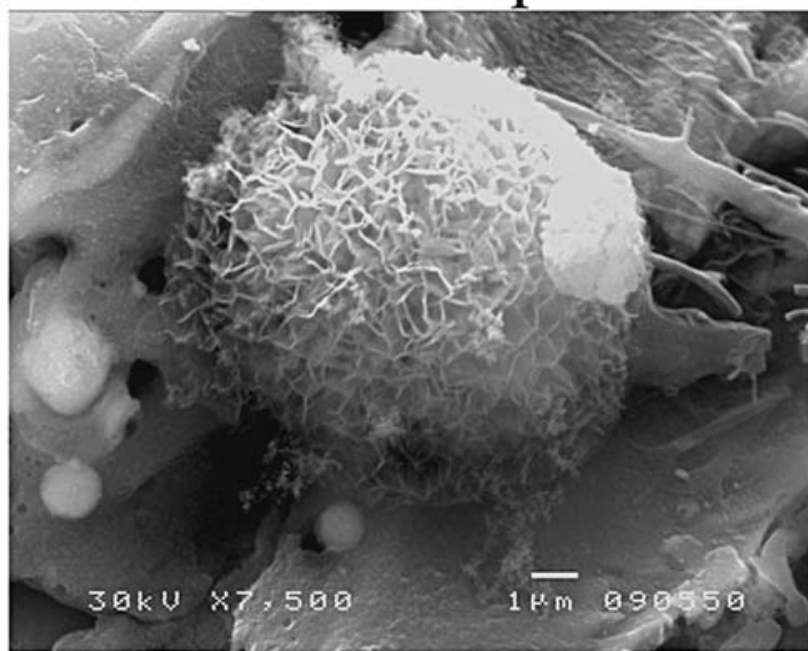

Fig. 3. SEM analysis of immature MoDCs cultivated for two days on polystyrene coverslips (Control), polystyrene coverslips in presence of LPS $(0.5 \mu \mathrm{g} / \mathrm{mL})$ or Ni-Ti samples. The parameters of the analysis are indicated.

of $\mathrm{CD}^{+} \mathrm{T}$ cells with control MoDCs. Other cytokines analysed (IFN- $\gamma$, TNF- $\alpha$, IL-1 $\beta$, TNF- $\beta$, and IL-4) were not modified significantly.

\section{Phenotypical and functional changes of LPS-treated MoDCs induced by Ni-Ti RS ribbons}

The immunostimulatory effect of MoDCs can be achieved upon their maturation. To investigate how Ni-Ti RS ribbons modulate the immunogenic properties of MoDCs we used LPS as a DCs maturation stimulus. At first, the expression of HLA-DR, CD86, CD83 and CD40 molecules were tracked after two days of cultivating MoDCs in the presence of LPS or a combination of LPS and Ni-Ti RS ribbons (Fig. 6). As expected, LPS led to phenotypic maturation of MoDCs, as judged by the strong up-regulation of all tested markers. We found that Ni-Ti RS ribbons lowered slightly the expression of HLA-DR, but increased the expression of CD40 and CD86 co-stimulatory molecules on MoDCs compared to LPS-treated, control MoDCs.

By analysing cell-free culture supernatants we found, unexpectedly, that Ni-Ti RS ribbons enhanced the production of IL-12 by MoDCs in the presence of LPS. Simultaneously, the ribbons lowered the production of IL-23 (Fig. 7a). Additionally, we found a higher proliferation rate of allogenic $\mathrm{CD}^{+} \mathrm{T}$ cells in co-culture with Ni-Ti ribbons-treated MoDCs at 1:40 $\mathrm{MoDC} / \mathrm{CD}^{+} \mathrm{T}$ cell ratio, compared to LPS-treated control MoDCs (Fig. 7b, Fig. 8).

The analysis of cytokines from co-culture supernatants revealed the most intriguing results (Fig. 7c). MoDCs cultivated in the presence of a combination of LPS and Ni-Ti RS ribbons possessed a pronounced Th1 polarising capacity compared to LPS-treated control MoDCs, as judged by the higher production of IFN- $\gamma$, IL- 6 and IL-8. In contrast, the levels of IL-17 and IL-10 were significantly lower. The levels of IL-4 were also lower in the co-cultures, but the differences were not statistically significant.

\section{Surface microstructure and depth profiles of $\mathrm{Ni}$ - $\mathrm{Ti}$ $\mathrm{RS}$ ribbons}

The changes of MoDCs morphology, phenotype and function occurring at the contact with Ni-Ti RS ribbons motivated us to analyse the surface microstructure and depth profiles of Ni-Ti RS ribbons before and after cultivation of the ribbons in cell-culture medium in order 

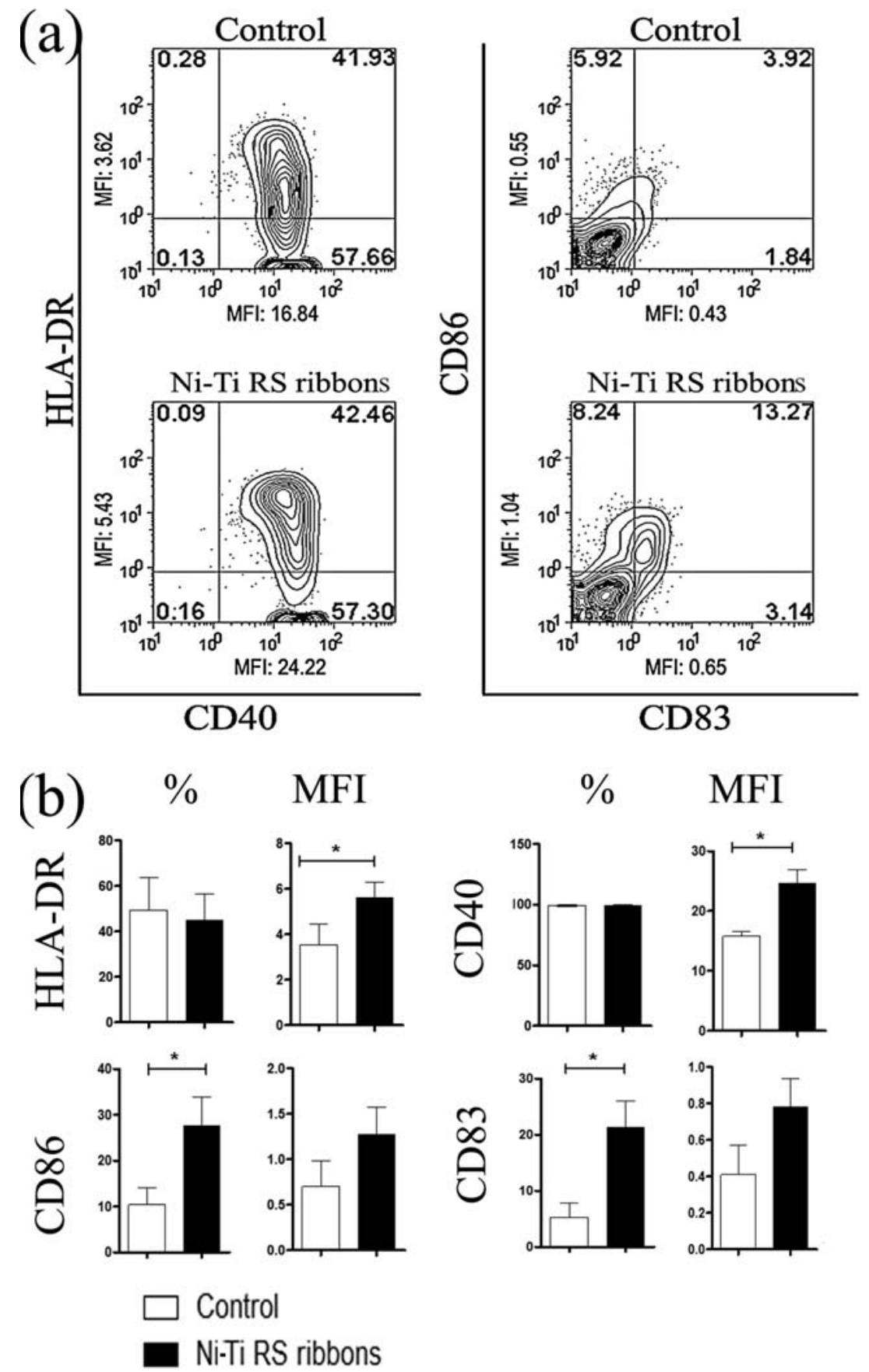

Fig. 4. Phenotypical analysis of immature MoDCs cultivated on Ni-Ti RS ribbons for two days. (a) Contour plots are presented, showing the percentage of positive cells and the Mean Fluorescence Intensities (MFI) for the indicated surface molecules. The data obtained from one representative experiment is shown. (b) The data is presented as mean \pm SD of four independent experiments. ${ }^{*} p<0.05$ corresponding to control samples (Wilcoxon matched pairs test).

to understand better the possible mechanisms involved in the processes.

Therefore, the aim of this study was to investigate thoroughly the surface of Ni-Ti RS ribbons by using SEM, Auger spectroscopy and XPS analysis. Fig. 9a shows the SEM micrograph of the Ni-Ti RS ribbons surface. The micrograph depicts a relatively smooth surface of the ribbons usually found in most places analysed, although some irregularly appearing embossments could be observed in some places as well. XPS survey spectra analysis on the Ni-Ti RS ribbons' surface was performed after 5 min of sputtering with $\mathrm{Ar}^{+}$ions at $3 \mathrm{keV}$ to remove surface contaminations. The spectra revealed the presence of Ni, Ti, O and $\mathrm{C}$ as dominant elements (Fig. 9b). We found that the surface of $\mathrm{Ni}-\mathrm{Ti} \mathrm{RS}$ ribbons is covered by a continuously dense Ti-oxide film, while $\mathrm{C}$ and $\mathrm{O}$ were still present on the surface, probably as contaminations. $\mathrm{Ni}$ and $\mathrm{Ti}$ were also found in an intermetallic state at the concentration of $3.2 \mathrm{at} \%$ and 1.6 at $\%$, respectively. 
(a)

(b)
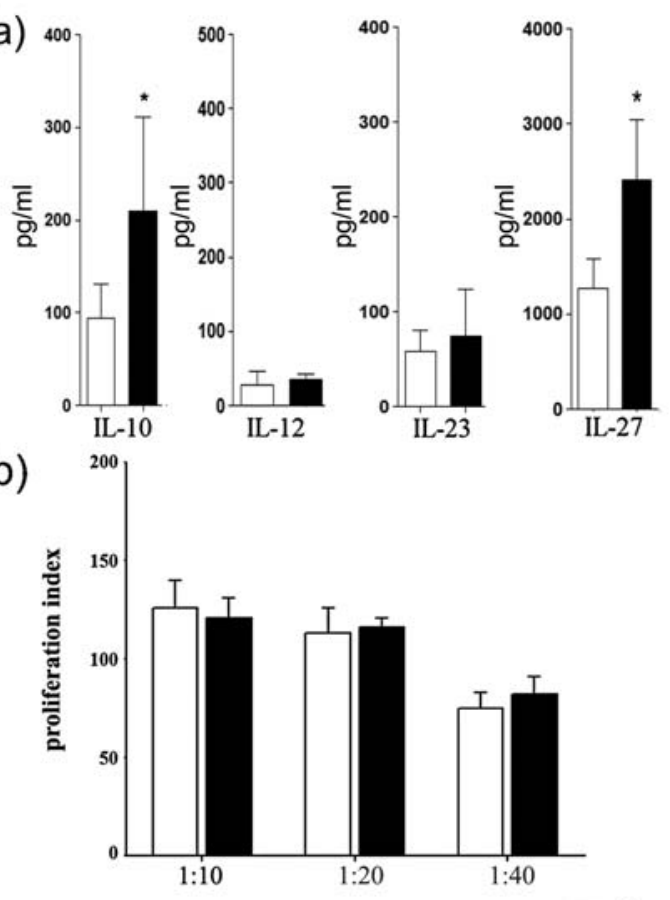
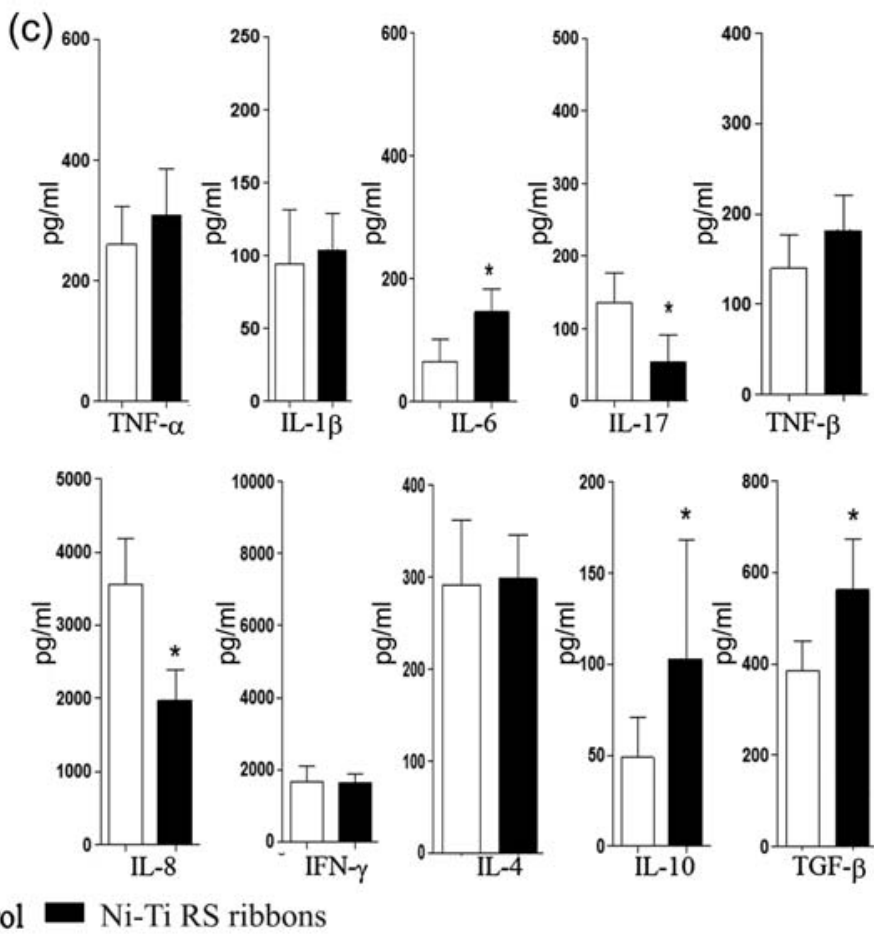

Fig. 5. Functional responses of immature MoDCs to Ni-Ti RS ribbons. MoDCs were cultivated in the absence (Control) or in the presence of Ni-Ti RS ribbons for two days. After that, the supernatants were collected and the cells were co-cultured with allogenic $\mathrm{CD}^{+}{ }^{+} \mathrm{T}$ cells using different cell-to-cell ratios, as indicated. After 5 days, the proliferation of cells and the cytokine production were assessed in the co-cultures. (a) Levels of cytokine in MoDC cultures. (b) Proliferation of allogenic $\mathrm{CD}^{+} \mathrm{T}$ cell in co-culture. (c) Levels of cytokines in the co-culture supernatants. The data shown in (a) and (c) represents mean $\pm \mathrm{SD}$ of four independent experiments, each carried out in duplicates. ${ }^{*} p<$ 0.05 compared to control (Wilcoxon matched pairs test). (b) The data represent mean index of proliferation $\pm \mathrm{SD}$ of sixplicates from one independent experiment out of three with similar results (One-way ANOVA). The other two experiments are provided in Fig. 8.

High resolution XPS spectra analysis was taken to investigate the Ti and Ni binding energies. The Ti 2p XPS spectrum (Fig. 9c) looked complex and was fitted best with three curves. Two of the fitting curves possess peaks with binding energies at $458.7 \pm 0.4 \mathrm{eV}$ and $463.9 \pm 0.5$ $\mathrm{eV}$ corresponding to $\mathrm{Ti}^{4+}\left(\mathrm{TiO}_{2}\right) 2 \mathrm{p}_{3 / 2}$ and $\mathrm{Ti}^{4+}\left(\mathrm{TiO}_{2}\right) 2 \mathrm{p}_{1 / 2}$ respectively. The third fitted curve, with a peak at 454.7 $\pm 0.4 \mathrm{eV}$, corresponds to $\mathrm{Ti}$ in an intermetallic state $\left(\mathrm{Ti}^{\mathrm{Ni}-}\right.$ Ti) $2 p_{1 / 2}$. High resolution XPS spectra of Ni $2 p$ (Fig. 9d) showed two peaks with binding energies at $853.8 \pm 0.3 \mathrm{eV}$ and $870.5 \pm 0.4 \mathrm{eV}$ associated with $\mathrm{Ni}^{\mathrm{Ni}-\mathrm{Ti}} 2 \mathrm{p}_{3 / 2}$ and $2 \mathrm{p}_{1 / 2}$ in the intermetallic state. It should be pointed out that no Ni-oxide peak $(\sim 857 \mathrm{eV})$ could be detected on Ni-Ti RS ribbons in our experiments. A small satellite structure, separated from the main peaks by about $7 \mathrm{eV}$ was also present. A similar structure was detected on XPS spectra of Ni-Ti alloys (Chu et al., 2009).

AES depth profiles were performed to determine the thickness of the surface oxide layer on Ni-Ti RS ribbons. No $\mathrm{Ar}^{+}$sputtering was performed prior to analysis of the non-conditioned sample, so the concentration of $\mathrm{Ni}$ on the surface of the ribbons was much lower and concentration of $\mathrm{O}$ much higher compared to those obtained by XPS analysis (Fig. 10a). The oxygen depth profile shows a peak close to the top surface, whereas $\mathrm{Ni}$ and Ti profiles show minimal concentrations. Afterwards, the concentration of $\mathrm{O}$ decreased and $\mathrm{Ni}$ and $\mathrm{Ti}$ concentrations increased to a steady state value after $30 \mathrm{~min}$ of sputtering (Fig. 10b). If the oxide thickness is estimated by taking the depth where the O signal drops to $50 \%$ of the maximum value, the thickness of the Ti-oxide film on Ni-Ti RS ribbons was around 12 $\mathrm{nm}$. In addition, AES spot analysis showed no significant differences in the chemical compositions between the embossments and the smooth surface layer, suggesting that a relatively uniform layer is placed on top of the Ni-Ti RS ribbons (Fig. 10a).

After 2 days of conditioning the Ni-Ti RS ribbons in the complete culture medium the AES depth analysis was repeated and we found very interesting results. The surface concentrations of $\mathrm{O}$, Ti and $\mathrm{Ni}$ were much lower, and the concentration of $\mathrm{C}$ was much higher than before conditioning. Furthermore, many places analysed had no detectable level of Ni (Fig. 10c represents an example). However, the presence of new elements on the surface was detected, such as $\mathrm{P}, \mathrm{Cl}$ and, intriguingly, $\mathrm{Zn}$. Each of the detected elements returned to the basic level obtained before conditioning after $7.5 \mathrm{~min}$ of sputtering (Fig. 10d). The estimated thickness of the oxygen layer, calculating from the depth with the maximal O concentration, was around $15 \mathrm{~nm}$. 


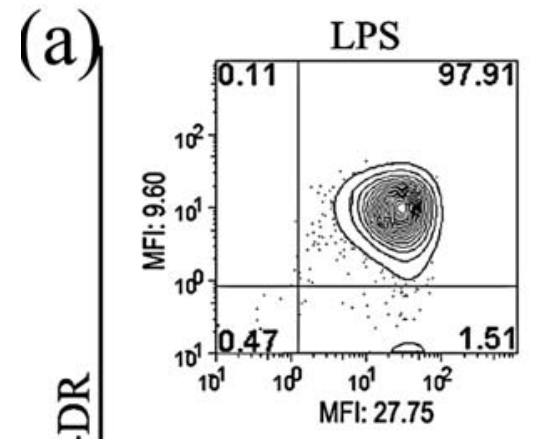

$\mathrm{Ni}-\mathrm{Ti}$ RS ribbons/LPS

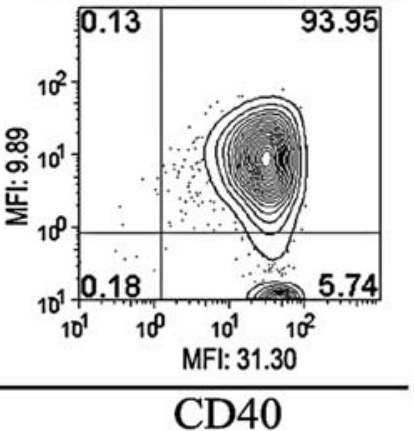

(b) $\%$
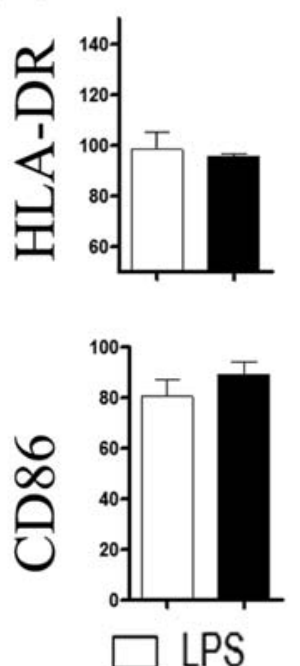

LPS

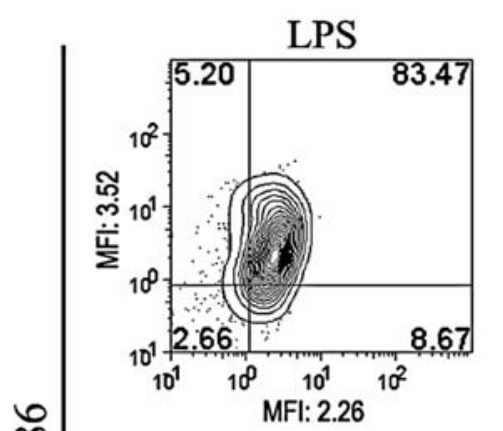

Ni-Ti RS ribbons/LPS

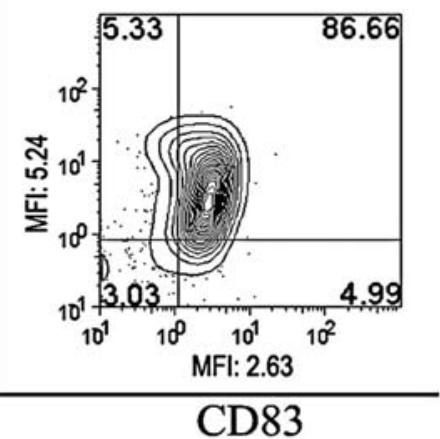

$\%$

MFI
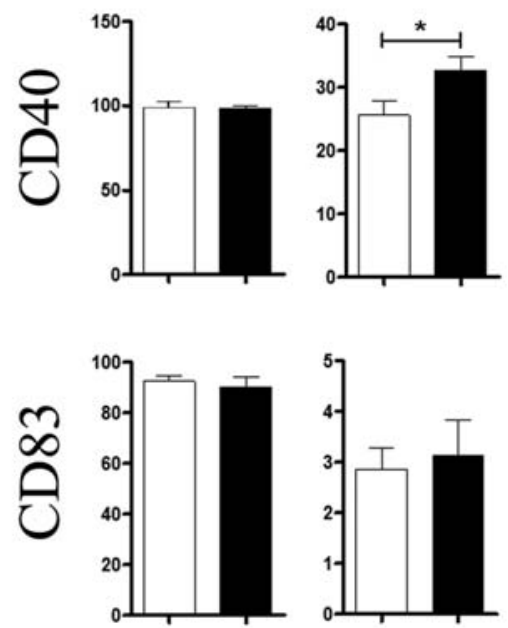

Fig. 6. Phenotypical analysis of MoDCs cultivated on Ni-Ti RS ribbons in the presence of LPS for two days. (a) Contour plots are presented, showing the percentage of positive cells and the Mean Fluorescence Intensities (MFI) for the indicated surface molecules. The data obtained from one representative experiment is shown. (b) The data are presented as mean $\pm \mathrm{SD}$ of four independent experiments. ${ }^{*} p<0.05$ corresponding to control samples (Wilcoxon matched pairs test).

\section{Discussion}

Biocompatibility of Ni-Ti RS ribbons and their influence on the morphology and phenotype of MoDCs

We continued the biocompatibility assessment of $\mathrm{Ni}$-Ti RS ribbons on MoDCs in cultures following the earlier paper on human PB-MNCs (Rudolf et al., 2010). Up to now, the biological effects of Ni-Ti SMAs were studied on various animal and human cells (Shabalovskaya, 2002; Es-Souni and Fischer-Brandies, 2005), but never on DCs. We confirmed that Ni-Ti RS ribbons were not cytotoxic for MoDCs, in contrast to highly cytotoxic control Ni-Ti plates, which induced both apoptosis and necrosis. A possible cause for such adverse effects of the plates could be released $\mathrm{Ni}$ ions in the MoDCs culture medium or free $\mathrm{Ni}$ on the surface of the plates. Ni can cause the formation of oxygen radicals, DNA damage and the inactivation of tumour 

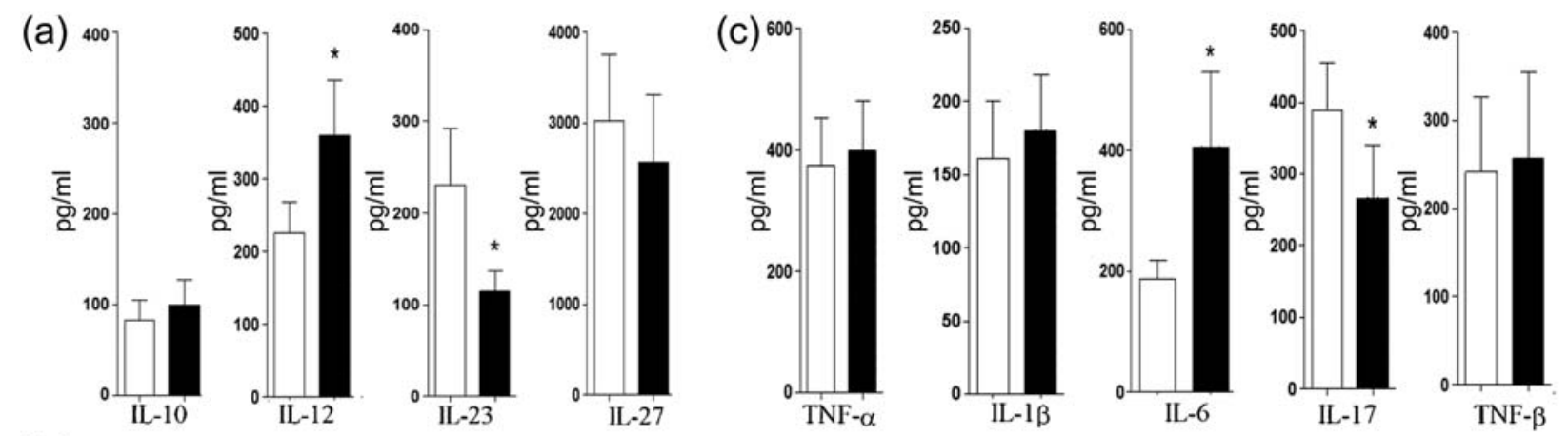

(b)

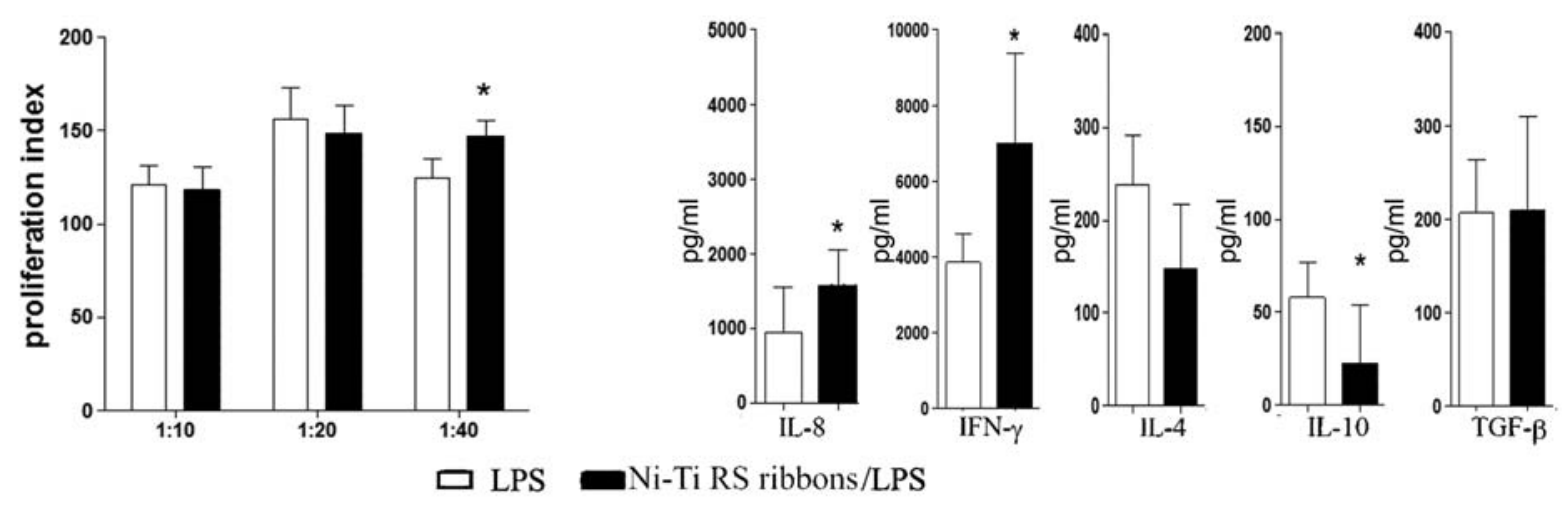

Fig. 8. Functional responses of MoDCs to Ni-Ti RS ribbons in the presence of LPS. MoDCs were cultivated in the absence (Control) or in the presence of Ni-Ti RS ribbons for two days. After that, the supernatants were collected and the cells were co-cultured with allogenic $C D 4^{+} \mathrm{T}$ cells using different cell-to-cell ratios, as indicated. After 5 days, the proliferation of cells and the cytokine production were assessed in the co-cultures. (a) Levels of cytokine in MoDC cultures. (b) Proliferation of allogenic $\mathrm{CD}^{+} \mathrm{T}$ cell in co-culture. (c) Levels of cytokines in the co-culture supernatants. The data shown in (a) and (c) represents mean $\pm \mathrm{SD}$ of four independent experiments, each carried out in duplicates. ${ }^{*} p<0.05$ compared to control (Wilcoxon matched pairs test). (b) The data represent mean index of proliferation $\pm \mathrm{SD}$ of sixplicates from one independent experiment out of three with similar results. ${ }^{*} p<0.05$ compared to control (One-way ANOVA). The other two experiments are provided in Fig. 8.

suppressor genes (Klein et al., 1991). Recent works utilising microarray analysis indicated that $\mathrm{Ni}$ ions can up-regulate a range of candidate genes controlling cell differentiation, death, cholesterol metabolism and apoptosis ( $\mathrm{Lu}$ et al., 2009). Apoptosis and necrosis are considered functionally and morphologically distinct forms of cell death, which is highly dependent on the energy metabolism of the cell. It was shown that cells triggered to undergo apoptosis will die by necrosis when the ATP level is low (Leist et al., 1997). Based on these results it can be postulated that the released $\mathrm{Ni}$ ions from control Ni-Ti plates induced apoptosis as we demonstrated in this study; and by blocking the energy metabolism, causing the formation of oxygen radicals and DNA damage, induced necrosis as well. In line with this hypothesis, Lifeng et al. (Lifeng et al., 2011) showed recently that bare $\mathrm{Ni}-\mathrm{Ti}$ alloys, characterised by a high surface concentration of $\mathrm{Ni}$, increased the expression of pro-apoptotic genes, and down-regulated genes controlling anti-apoptosis, protein biosynthesis, energy metabolism and DNA repair.

EDX analysis of Ni-Ti RS ribbons and control Ni-Ti plates revealed similar basic composition of the alloys. However, their surface microstructure was different and characterised by more pronounced intermetallic phases on control Ni-Ti plates. In addition, mechanical polishing used for preparation of Ni-Ti plates is a well known factor which affects both the surface microstructure and biocompatibility of Ni-Ti alloys (Shabalovskaya et al., 2008). Therefore, Ni could not be the only factor causing the cytotoxicity. It is possible that other factors introduced by mechanical polishing of Ni-Ti plates (Shabalovskaya et al., 2008), in contrast to non-polished Ni-Ti RS ribbons, could contribute to such an adverse effect.

\section{Morphological and phenotypical changes of MoDCs cultivated on Ni-Ti alloys}

Even though Ni-Ti RS ribbons were non-cytotoxic, we found a changed morphology in MoDCs cultivated on the ribbons, suggesting that the ribbons are not completely inert for MoDCs. It is known that, during maturation, DCs undergo many programmed morphological and phenotypical changes, including the formation of veils and dendrites (Fisher et al., 2008) involved in the establishment of appropriate DC-T cell interactions (Banchereau et al., 2000). Therefore, the surface morphology of DCs cultivated on the ribbons, as revealed by SEM, resembled that of maturing DCs. These findings are in accordance with the up-regulated expression of key DC markers, such as HLADR, co-stimulatory molecules (CD86 and CD40) and CD83, the most important DC maturation marker. Since 


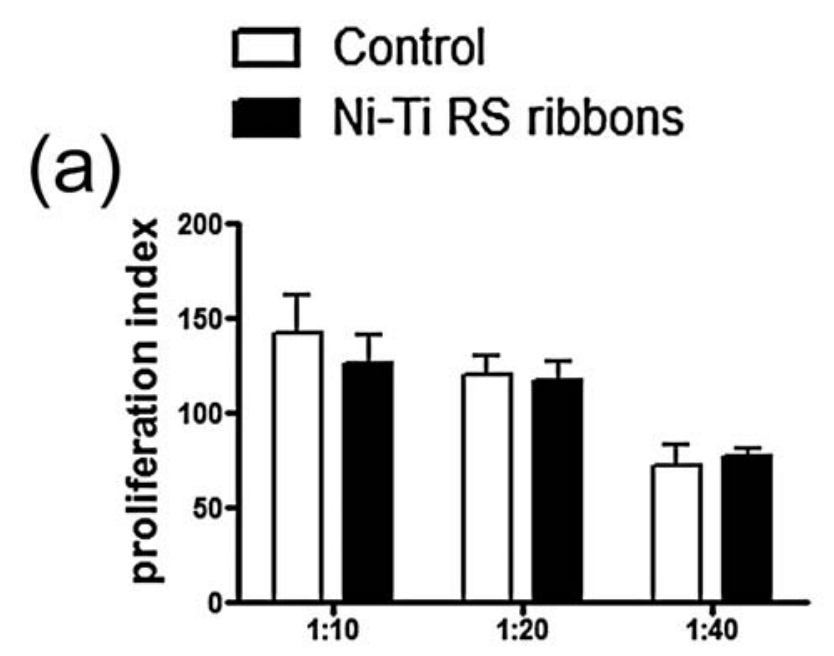

(b)
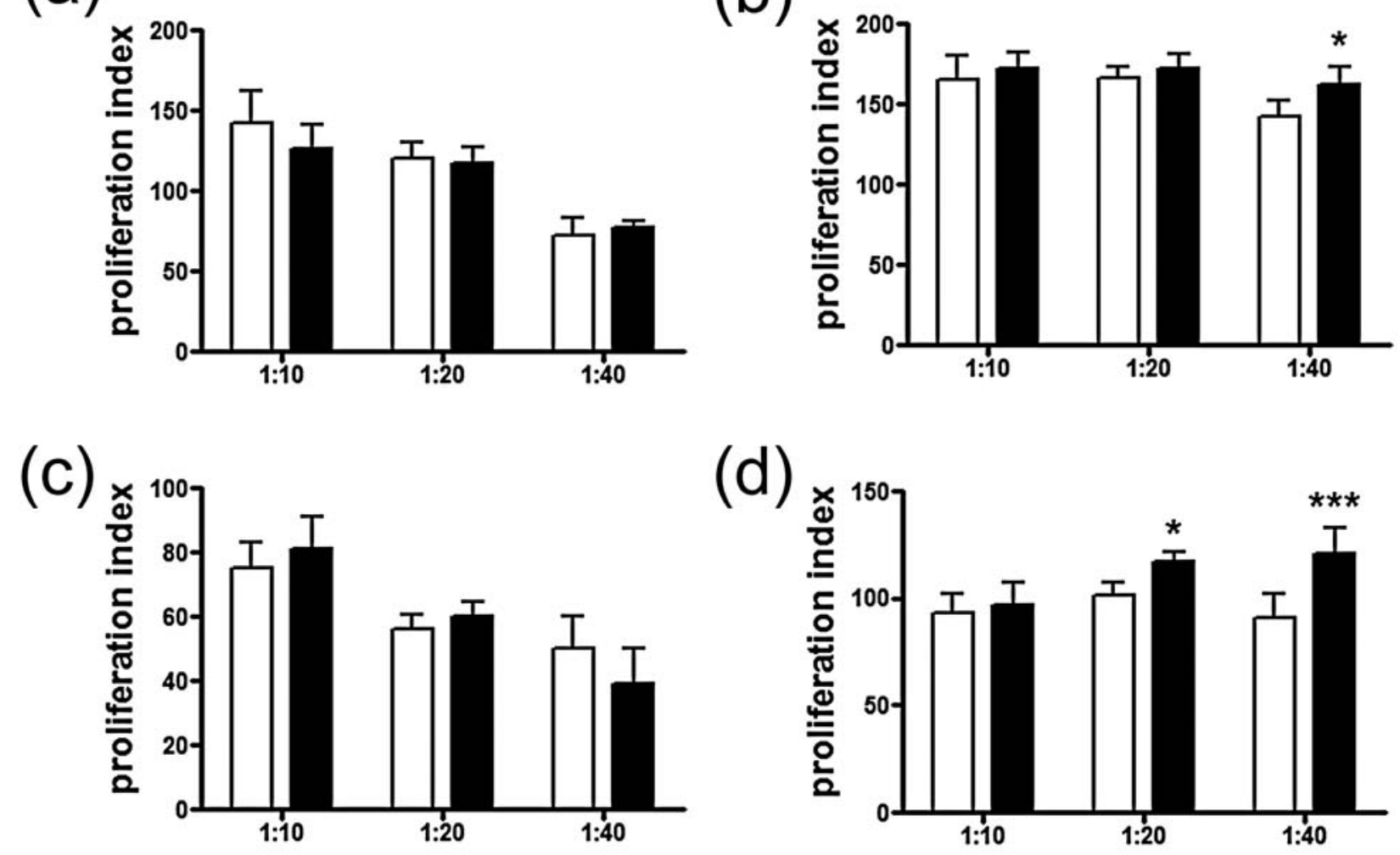

Fig. 6.Allostimulatory capacity of MoDC treated with Ni-Ti RS ribbons - additional data for the Figs. 5b and 7b. MoDCs were cultivated in the absence (Control) or in the presence of Ni-Ti RS ribbons for two days and then co-cultured with allogenic $\mathrm{CD}^{+} \mathrm{T}$ cells at different cell-to-cell ratios, as described in Materials and Methods. The results of alloreactive $\mathrm{CD}^{+} \mathrm{T}$ cell proliferation from Experiment 2 (a and b) and Experiment 3 (c and $\mathbf{d}$ ) are shown; (a) and (c): immature MoDCs as stimulators; (b) and (d) LPS-matured MoDCs as stimulators. The data are presented as the mean index of proliferation $\pm \mathrm{SD}$ of sixplicates. $* p<0.05, * * * p<0.005$ compared to control (one-way ANOVA).

we showed that their expression was significantly lower and dendrites were less elongated compared to mature MoDCs cultivated for 2 days with LSP, which is known to stimulate strong maturation of DCs, (Banchereau et al., 2000), it can be postulated that Ni-Ti ribbons initiated a process of semi-maturation of MoDCs (Lutz and Schuler, 2002). It is not easy to explain the mechanisms of these changes to MoDCs. Modulation of cell morphology depends on the reorganisation of actin filaments (F-actin) and the process could be modulated by $\mathrm{Ni}$ ions. Gunaratman and Grant (Gunaratnam and Grant, 2004) showed that only high concentrations of Ni can cause direct alteration in F-actin, leading to membrane blebbing, condensation of F-actin and death by necrosis. These findings are in accordance with our results regarding the morphology of MoDCs cultivated on control Ni-Ti plates. Accordingly, since Ni-Ti RS ribbons released an insignificant amount of $\mathrm{Ni}$, the changes in the morphology of MoDCs are most probably not caused by the direct impact of $\mathrm{Ni}$ ions on the cytoskeleton, but as a consequence of programmed changes that occurred during maturation of the MoDCs.
Improvement of the tolerogenic properties of MoDCs by Ni-Ti RS ribbons

The most important functional capability of MoDCs cultivated on Ni-Ti RS ribbons was their potentiation of cytokine production with tolerogenic capability (IL-10 and TGF- $\beta$ ) by allogenic $\mathrm{CD}^{+} \mathrm{T}$ cells. The levels of these cytokines correlated with increased production of IL-10 and IL-27 by MoDCs cultivated with Ni-Ti RS ribbons. Most of the effects of IL-10 and IL-27 on the cytokine network might be explained in our culture model system (Fig. 11). IL-27 is involved in the initiation of the Th1 response, inhibition of IL-17 and up-regulation of IL-10 production from $\mathrm{T}$ cells subsets, both in humans and mice (Yoshimura et al., 2006). On the other hand, IL-10 was shown to enhance the differentiation of IL-10-secreting $\mathrm{T}$ regulatory cells (Treg), thus providing a positive regulatory loop for its own induction, suppression of T cell proliferation and down-regulation of inflammation (Saraiva and O'Garra, 2010). Our results are in line with these observations showing that IL-10- and IL-27-producing MoDCs stimulated the production of IL-10 and TGF- $\beta$, 


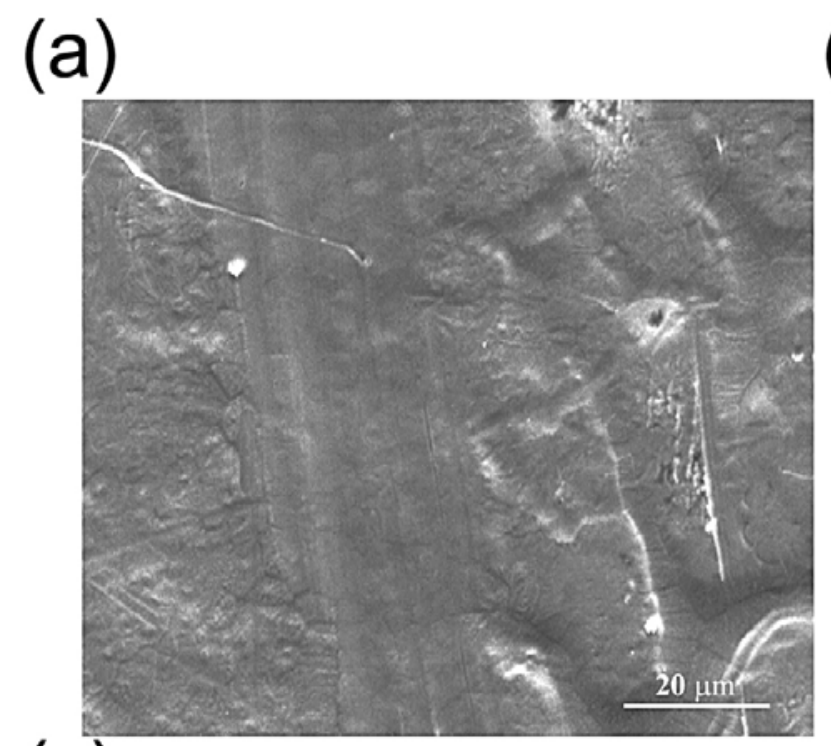

$(\mathrm{b})_{x 100}$
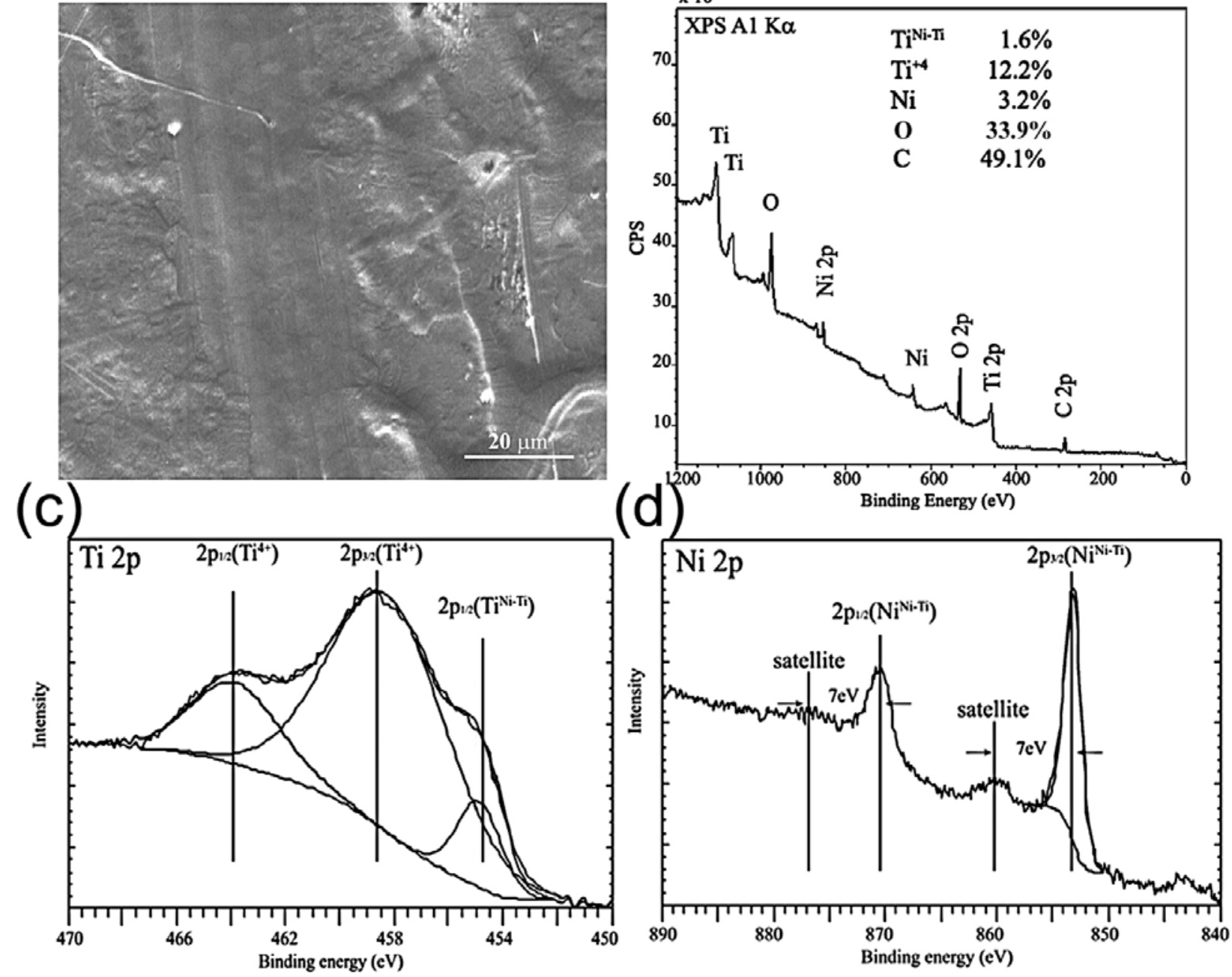

Fig. 9. Surface analysis of Ni-Ti RS ribbons. (a) The surface of Ni-Ti RS ribbons analysed by SEM. (b) XPS survey spectra. (c) High resolution XPS spectra of Ti2p and (d) Ni2p binding energies.

and inhibited strongly IL-17 and IL-8 production in MoDC/ $\mathrm{CD}^{+}{ }^{+} \mathrm{T}$ cells' co-cultures. Such a tolerogenic cytokine environment could be a major reason for the observed lack of allostimulation of CD4+ T cells, even though MHC class II and costimulatory molecules were up-regulated by $\mathrm{Ni}-\mathrm{Ti}$ $\mathrm{RS}$ ribbons. These results indicate that MoDCs experienced by Ni-Ti RS ribbons induce a tolerogenic environment after the contact with $\mathrm{CD} 4^{+} \mathrm{T}$ cells.

However, we also found in co-cultures with MoDCs cultivated with $\mathrm{Ni}$-Ti RS ribbons enhanced production of IL-6, a cytokine with both pro-inflammatory and antiinflammatory properties (Kishimoto, 2010). The source of this cytokine in the cultures could be Th2 cells, DCs or both (Kishimoto, 2010). However, CD4 ${ }^{+} \mathrm{T}$ cells, particularly their Th2 subset was most probably the predominant source of IL-6. Other cytokines detected in the co-culture system could also originate from $\mathrm{CD}^{+} \mathrm{T}$ cells, because the number of MoDCs in the cultures was very low. Except for a very low level of IL-8 (up to $100 \mathrm{pg} / \mathrm{mL}$ ), neither of the investigated cytokines were detected in the control supernatants with MoDCs cultivated alone (data not shown). The functional significance of this phenomenon is not clear. However, since IL-6 was shown to have a crucial role in the wound healing process in a model of skin excisions on IL- $6^{-/-}$and wild type mice (Lin et al., 2003), the potentially beneficial effects of this cytokine can be hypothesised upon implantation of Ni-Ti RS ribbons. The only paper describing the tolerogenic properties of SMAs, except for our previous one (Rudolf et al., 2010), was the finding of Lifeng et al. (Lifeng et al., 2011) who showed that biocompatible TiN-coated NiTi SMAs, in contrast to bare Ni-Ti SMAs, can induce the expression of IL-10 anti-inflammatory pathways in HUVEC cells. However, except for the detected change in the expression of particular genes, no further immunological investigations were made to explain the possible implications of such findings. Bearing in mind that the immature MoDCs in this experiment possess tolerogenic capability, one of the key properties of $\mathrm{Ni}-\mathrm{Ti}$ RS ribbons was the enhancement of this tolerogenicity. Such a finding could have significant clinical relevance in preserving and enhancement of tolerance to the implanted Ni-Ti SMA-based alloy and maintaining the peripheral tolerance to self antigens (Hu and Wan, 2011). However, 
(a)
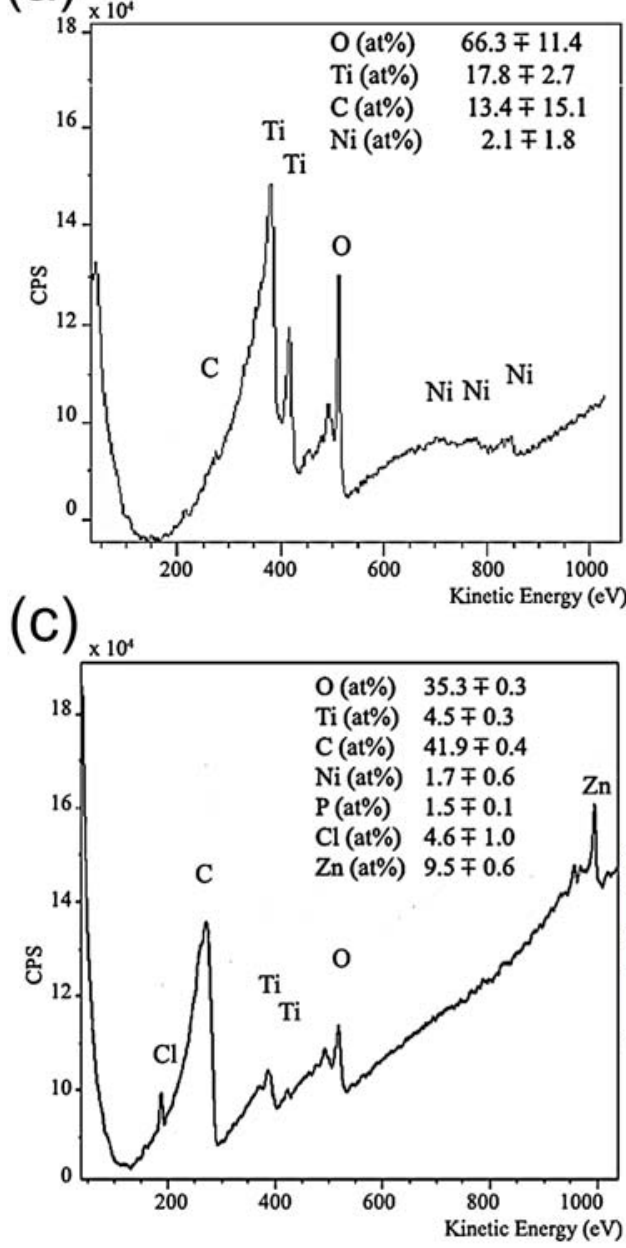

(b)

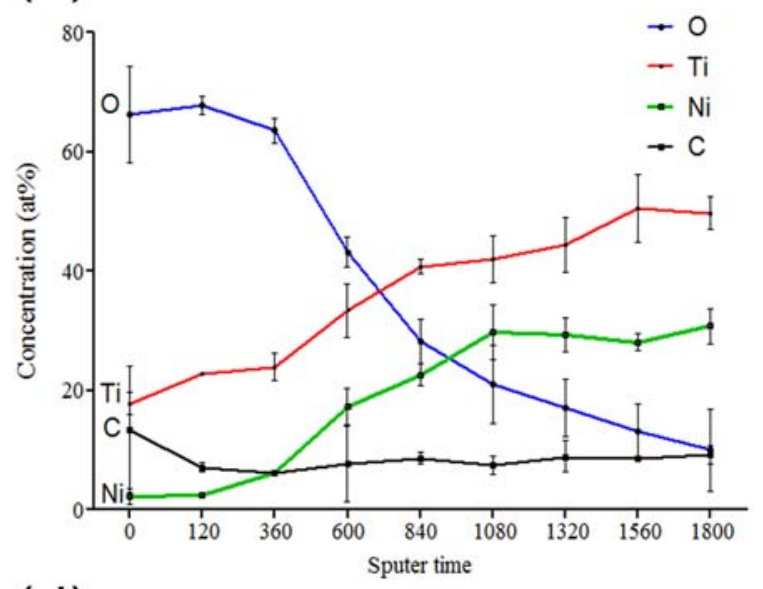

(d)

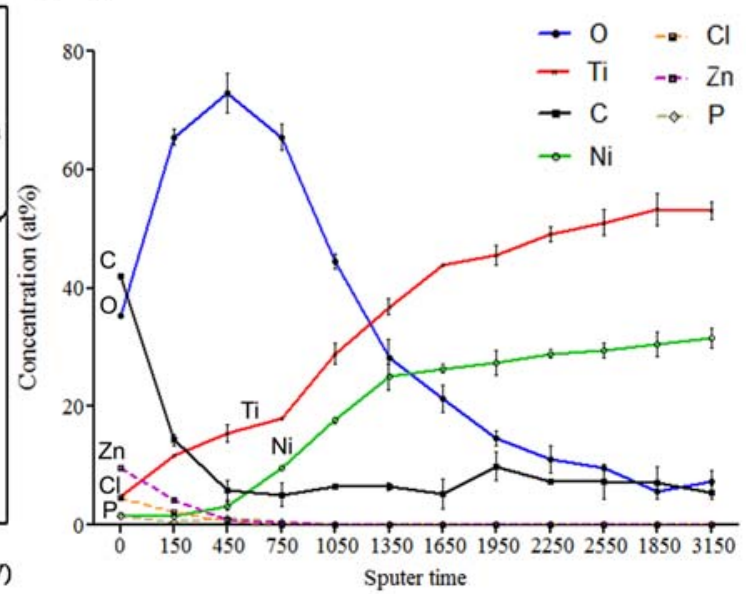

Fig. 10. Surface depth profile of Ni-Ti RS ribbons before and after conditioning in cell-free culture medium for 2 days. (a) A representative AES profile obtained before conditioning. (b) The corresponding AES depth profile showing compositional changes after each cycle of $\mathrm{Ar}^{+}$ion sputtering. (c) A representative AES profile obtained after the conditioning. (d) The corresponding AES depth profile showing compositional changes after each cycle of $\mathrm{Ar}^{+}$ion sputtering. Each value in depth profiles was made by averaging 3 places of AES analysis after each sputtering cycle.

more in vivo investigation of implanted $\mathrm{Ni}$-Ti RS ribbons should be performed in order to confirm such an effect.

\section{Modulation of MoDC functions by Ni-Ti RS ribbons under inflammatory conditions}

Upon encountering dangerous signals, such as pathogens, DCs mature and migrate to regional lymph nodes, where they activate antigen-specific $\mathrm{T}$ cells leading to an appropriate immune response (Banchereau et al., 2000). Therefore, our next goal was to investigate whether Ni-Ti RS ribbons possess similar tolerogenic effects in the presence of LPS, a pathogen-associated molecular pattern with known adjuvant properties (Banchereau et al., 2000). To understand the possible modifications induced by the addition of Ni-Ti RS ribbons, we should rationalise the effects of LPS alone. LPS ligates TLR-4 on DCs, activating both Myeloid Differentiation protein 88 (MyD88)-dependent and TIR domain-containing adaptor inducing IFN-beta (TRIF)-dependent pathways. The result is the activation of Nuclear Factor-kappa B (NF- $\kappa \mathrm{B})$, Activating Protein 1 (AP1), Interferon Responsive Factor (IRF)-3 and IRF-5 transcription factors which lead to increased expression of MHC and co-stimulatory molecules, pro-inflammatory cytokines and interferonresponsive genes (Kawai and Akira, 2010). As expected, LPS induced the strong maturation of MoDCs in our experiments, as judged by the high up-regulation of HLADR, CD40, CD86 and CD83 molecules. Furthermore, LPS-treated MoDCs increased strongly the production of IL-12, IL-23 and IL-27, compared to the control immature MoDCs. Consequently, we observed a pro-inflammatory polarisation of $\mathrm{CD}^{+} \mathrm{T}$ cells in co-cultures, characterised by Th1 and Th17 cytokine responses (Cucak et al., 2009; McAleer et al., 2010), as concluded by the higher production of IL-1 $\beta$, IL-6, IL-17, TNF- $\beta$ and IFN- $\gamma$.

The most interesting finding was that LPS-treated MoDCs that were experienced additionally by Ni-Ti RS ribbons possessed more pronounced Th1 polarising capacity compared to the LPS-treated control. Namely, we found increased IL12 production, down-regulated IL-23 and unchanged IL-27 


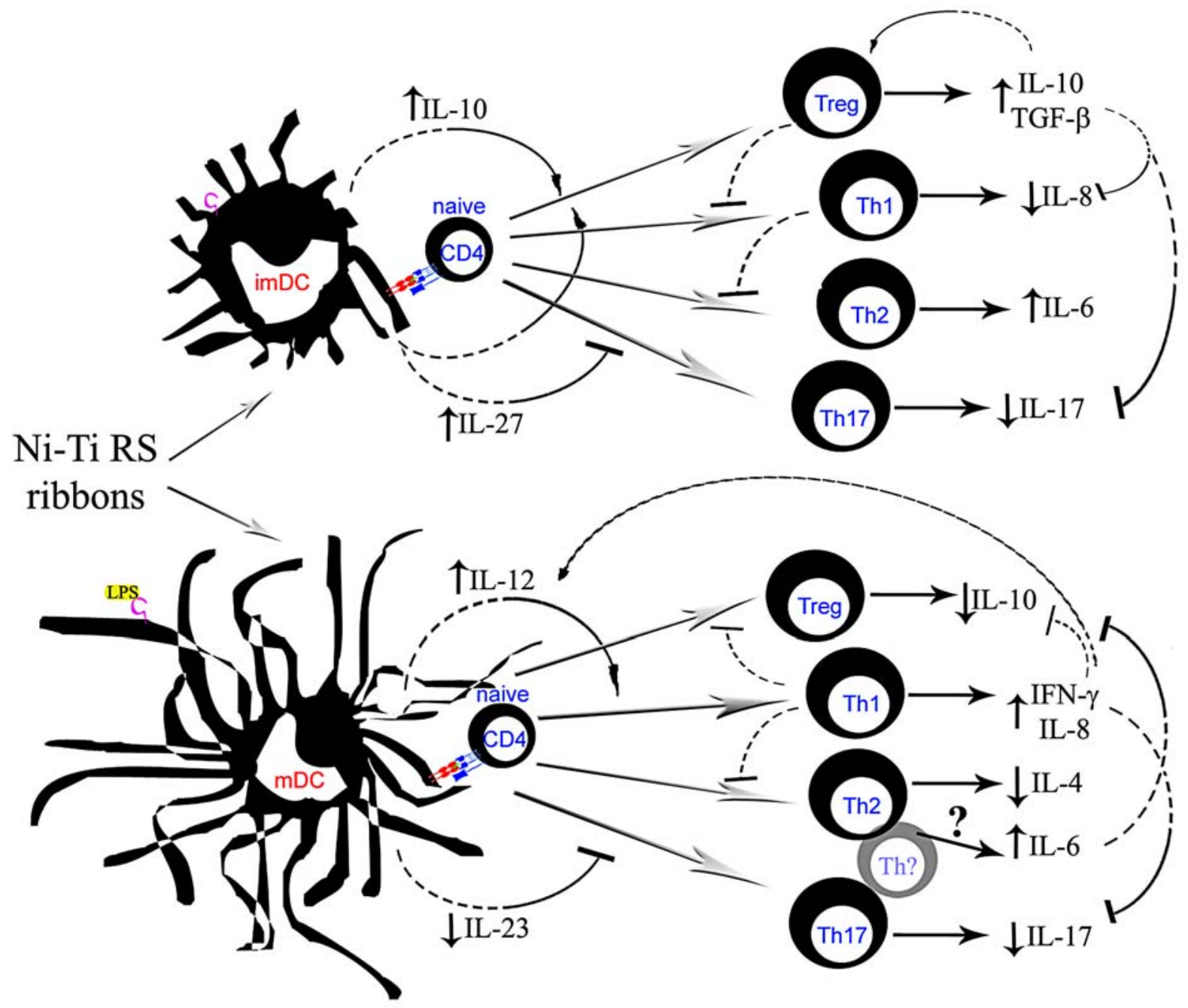

$\uparrow \downarrow$ Increased/decreased produciton compared to control cells

$\longrightarrow$ Differentiation
$\longrightarrow$ Production/Secretion
Stimulation/Up-regulation/Support

c Toll-like receptor 4

1. MHC class II: peptide complex

T cell receptor complex

CD4- co-receptor

Fig. 11. Hypothetical interactions of cytokines in the co-culture of MoDCs treated with Ni-Ti RS ribbons and $\mathrm{CD}^{+} \mathrm{T}$ cells. Immature MoDCs (imDCs) activated by Ni-Ti RS ribbons increased the production of IL-10 and IL-27, which might have induced the differentiation of $\mathrm{T}$ regulatory cells (Treg) in co-culture with $\mathrm{CD} 4^{+} \mathrm{T}$ cells, which was followed by increased production of IL-10 and TGF- $\beta$. These cytokines promoted the development of additional Treg, thus increasing their own production. On the other hand, these cytokines are most probably involved in the suppression of pro-inflammatory cytokines' production, such as IL-8 and IL-17, and the development of a Th1 subset. Inhibition of a Th17 subset could also be a direct effect of IL-27 produced by the imDCs. The increased production of IL-6 might have been the consequence of the inhibited differentiation of Th1 by Treg, a state that is known to promote Th2 development. LPS acting on TLR4 induced the maturation of DCs. The increased production of IL-12 by LPS-matured DCs (mDCs) in the presence of Ni-Ti ribbons most probably promoted the differentiation of the IFN- $\gamma$-producing Th1 subset in the co-culture. IFN- $\gamma$ is known to stimulate Th1 development further by a positive feedback loop, and to inhibit the differentiation of other Th subsets, including Th2, Th17 and Treg subsets. Furthermore, down-regulation of IL-23 production by MoDCs lowered the supporting effect of this cytokine on the Th17 differentiation and IL-17 production. What remains a mystery, however, is the production of IL-6 in those co-cultures. The increased production of IL-6 could either be regulated specifically by a Th2 subset, or its source could be some other Th subset that is not suppressed by IFN- $\gamma$. 
production by these MoDCs. These cytokines belong to the IL-12 family, where IL-12 (p35/p40) was shown to stimulate IFN- $\gamma$ production preferentially from $T$ cells (Magram et al., 1996), IL-23 (p19/p40) stimulates IL-17 (Aggarwal et al., 2003), and IL-27 (p28/EBI3) stimulates IFN- $\gamma$ and IL-10 production from $\mathrm{T}$ cells, while inhibiting IL-17 (Yoshimura et al., 2006). In our study the increased IL-12 production correlated with IFN- $\gamma$ production, whereas decreased production of IL-23 correlated with decreased production of IL-17 (Fig. 11). IL-23 has a significant role in the growth of Th17 cells and stabilisation of transcription factors (STAT3, ROR $\gamma \mathrm{t}$, and ROR $\alpha$ ) that are crucial for Th17 development. Th17 cells were shown to produce IL-17, IL-17F and IL-22, thereby inducing a massive tissue reaction owing to the broad distribution of the IL-17 and IL-22 receptors (Korn et al., 2009). In line with this, down-regulation of IL-17 production mediated by both immature and LPS-matured MoDCs could represent an important anti-inflammatory mechanism that Ni-Ti RS ribbons could induce upon implantation. The IL$12 /$ IFN- $\gamma$ enriched environment most probably caused the lower production of Th2 and Treg cytokines (IL-4 and IL-10) in the co-cultures, since it was shown that IL-12 and IFN- $\gamma$ through T-bet inhibit GATA-3-dependent differentiation and proliferation of Th2 cells (Kaiko et al., 2008). Additionally, IFN- $\gamma$ is shown to inhibit Extracellular Receptor Kinase (ERK)- and p38-dependent IL-10 production by macrophages and DCs, as well as TLR-induced IL-10 production, by antagonising the phosphatidylinositol-3-kinase - protein kinase B (PI3K-AKT) pathway (Hu et al., 2006). Since the levels of IL-27 were not changed significantly, it can be postulated that its effect on Th1/Th17 polarisation was lesser, compared to IL-12 and IL-23. The increased allostimulatory capacity of MoDCs observed at 1:40 $\mathrm{MoDC} / \mathrm{CD} 4^{+} \mathrm{T}$ cell ratio could be a consequence of the more pronounced Th1 cytokine environment which led to down-regulation of antiproliferative cytokines, such as IL-10, as well as to increased expression of co-stimulatory molecules. As mentioned earlier, the increased IL-6 production, which was also detected in the co-cultures of MoDCs treated with Ni-Ti RS ribbons in the presence of LPS, could have beneficial clinical effects in the wound healing process and angiogenesis (Kishimoto, 2010). However, under inflammatory conditions DCs in the close contacts with Ni-Ti implants can be activated additionally, leading to the development of unwanted immune or autoimmune responses. Therefore, these effects should be investigated in more detail in further experiments.

\section{Surface microstructure of Ni-Ti RS ribbons}

In our previous papers (Kneissl et al., 2006; Mehrabi et al., 2009) we described the process of Rapid Solidification by melt spinning and its influence on the microstructure and improvement of the shape memory properties of $\mathrm{Ni}-\mathrm{Ti}$ SMAs. Since the surface of an alloy is the predominant factor determining the outcome of any material-to-cell interaction (Shabalovskaya, 2002), in this work we investigated for the first time the surface of Ni-Ti RS ribbons aiming to understand its biological effects. We showed that the surface of $\mathrm{Ni}$ - Ti RS ribbons was relatively smooth with embossments appearing irregularly. Since AES spectroscopy showed no difference in chemical composition between the embossments and flat surfaces, the embossments possibly lay beneath the surface layer and they most probably originate from the metastable solidification process of the melt spinning technique (Anzel et al., 2009; Unterweger et al., 2005).

We showed that the surface of Ni-Ti RS ribbons is covered by a thin, dense Ti-oxide film, composed predominantly of $\mathrm{TiO}_{2}$ phase. However, the small amount of $\mathrm{Ni}$ and $\mathrm{Ti}$ in the intermetallic state present on their surface could affect the corrosion stability of the ribbons with the time. Therefore, possible additional coating procedures such as (Ti, O, N)/Ti (Sun et al., 2011) or TiN (Lifeng et al., 2011) coating, or oxidising procedures such as $\mathrm{H}_{2} \mathrm{O}_{2}$-oxidation (Sun and Wang, 2010) or anodisation (Chu et al., 2009), as already applied for Ni-Ti alloys, should be considered. The presence of $\mathrm{C}$ on the surface of Ni-Ti RS ribbons may be attributed to the surface contamination by carbon containing molecules absorbed from the environment (Chu et al., 2009). Knowing that $\mathrm{Ni}$-oxide could be substituted easily with $\mathrm{Cl}^{-}$ions from an extracellular solution through the $\mathrm{Ni}-\mathrm{OH}$ intermediary state (Williams and Williams, 1996), it should be pointed out that no Ni-oxide was detected on Ni-Ti RS ribbons. The Ti-oxide thickness was estimated to be around $12 \mathrm{~nm}$, which is in line with other reports showing that the Ti-oxide film thicknesses range between 7 and $70 \mathrm{~nm}$, depending on the treatment (Shabalovskaya, 1996). However, the thickness of the Ti-oxide layer is not as important as the density and structure of the layer. In line with this, several papers suggest that a homogenous smooth thin oxide surface gives better corrosion protection than the thicker one encountered in native samples (Trepanier et al., 1998; Es-Souni and FischerBrandies, 2005). Furthermore, the exposure of Ni-Ti SMAs to biological solutions was shown to influence significantly their surface properties (Trepanier et al., 1998; Wever et al., 1998). We found that the thickness of the oxygen layer after conditioning in a cell-free culture medium increased and the lower boundary of the oxygen layer was $10 \mathrm{~nm}$ deeper compared to a non-conditioned sample. In line with earlier findings (Trepanier et al., 1998; Wever et al., 1998), including our own with Cu-Al-Ni SMAs (Colic et al., 2010), we detected a small increase in the thickness of the oxygen layer in Ni-Ti RS ribbons, along with a $6 \mathrm{~nm}$ increase in the deposition layer. The presence of deposited $\mathrm{P}$ and $\mathrm{Cl}$ ions after conditioning was well expected, since RPMI medium contains high levels of these elements. However, since the basal RPMI medium does not contain $\mathrm{Zn}$ ions, we suppose that the adsorbed $\mathrm{Zn}$ originates most probably from FCS. Messer et al. (Messer et al., 1982) showed much earlier that the concentration of $\mathrm{Zn}$ in FCS is around $2.8 \mathrm{ppm}$. Since we found a much higher concentration of this ion on the surface of Ni-Ti RS ribbons, $\mathrm{Zn}$ could have been adsorbed from the culture medium onto the $\mathrm{TiO}_{2}$ surface layer, through a process studied thoroughly by Hasany et al. (Hasany et al., 1991). At pH7, $\mathrm{Zn}$ is predominantly in the form of $\mathrm{Zn}^{2+}(99.33 \%)$, which drives its adsorption onto the negatively charged $\mathrm{TiO}_{2}$ layer. This finding is very interesting, since $\mathrm{Zn}$ can have various biological effects depending on its concentration (Rink and Haase, 2007).

We found that $\mathrm{Ti}$ was not released into the culture medium from the samples, most probably owing to the fact 
that it oxidises easily, building a protective $\mathrm{TiO}_{2}$ surface layer. In this context, improved biocompatibility due to this biologically inert oxide layer is one of the reasons for the wide biomedical application of Ti-based implants (Es-Souni and Fischer-Brandies, 2005). Ni-Ti control plates released up to $120 \mathrm{mg} / \mathrm{L}$ of $\mathrm{Ni}$, but this concentration was more than $50 \%$ lower than the concentration of $\mathrm{Ni}$ ions released from the pure Ni plates. The most probable explanation for this observation is that Ti's tendency to react with $\mathrm{O}$ is much higher than $\mathrm{Ni}$, which leads to the building of an insoluble $\mathrm{TiO}_{2}$ surface layer acting as a barrier for further $\mathrm{Ni}$ release. On the other hand, the regular crystal lattice of Ni-Ti exhibits high atomic bonding forces with mixed covalent and metallic character, meaning that it is difficult for atoms to leave the bulk material easily (Es-Souni and Fischer-Brandies, 2005). In contrast to Ni-Ti plates, NiTi RS ribbons showed insignificant Ni release in culture medium $(20 \mu \mathrm{g} / \mathrm{L})$. This level of Ni ions is much lower than the provisional WHO guideline value of daily intake of $\mathrm{Ni}$ by food $(82-406 \mu \mathrm{g} / \mathrm{L})$ and corresponds to the value for drinking water and for whole blood and plasma/serum content of $\mathrm{Ni}$ in healthy persons $(5-25 \mu \mathrm{g} / \mathrm{L})$ (Es-Souni and Fischer-Brandies, 2005). Therefore, according to the microstructure analysis, it seems that the surface Ti-oxide layer structured by the melt-spinning is the most important factor that almost entirely prevents the Ni leakage from the surface of Ni-Ti RS ribbons.

\section{Possible mechanisms of the immunomodulatory properties of Ni-Ti RS ribbons}

We showed that MoDCs adhered to the surface of Ni-Ti RS ribbons, which could represent an important signal for maturation of MoDCs. Integrins were shown to play particularly important roles in responses to TiN-coated Ni-Ti SMAs (Lifeng et al., 2011) and other biomaterials (Rogers and Babensee, 2011), so further investigations are needed to evaluate their roles in the immunomodulatory effects of the Ni-Ti RS ribbons. However, other factors could also be involved, such as $\mathrm{Ti}$ and $\mathrm{Ni}$ ions on the surface of NiTi RS ribbons. Ti ions, for example, were shown to alter significantly MoDCs' properties, resulting in an enhanced $\mathrm{T}$ lymphocyte reactivity and deviation towards a Th1 type immune response (Chan et al., 2009). Ni was shown to induce the phosphorylation of ERK, Jun N-terminal kinase (JNK), and p38, thus regulating the maturation and expression of CD83, CD86, CCR7 and IL-12 production by DCs (Aiba et al., 2003). Recently, an interesting study showed that Ni ions down-regulate strongly tripartite motif containing (Trim) 23 gene expression (Lu et al., 2009), a regulator of the NF- $\kappa \mathrm{B}$ essential modulator (NEMO) (McNab et al., 2011), which could be an important mechanism for the tolerogenic behaviour in Ni-Ti SMAs. Even though the conditioned medium contained hardly detectable amounts of these elements, $\mathrm{Ti}$ and $\mathrm{Ni}$ ions were detected on the surface of Ni-Ti RS ribbons, even after conditioning. It is possible that the local concentration of available $\mathrm{Ni}$ and $\mathrm{Ti}$ ions at the place of close contact between MoDCs and Ni-Ti RS ribbons is higher than the one detected in the conditioned medium, leading to the observed immunomodulatory effects on MoDCs.
The most intriguing finding in our study was the presence of $\mathrm{Zn}$ ions after conditioning in complete culture medium after 2 days. Zn ions are proved as important signalling molecules in immune cells, particularly DCs in response to LPS (Rink and Haase, 2007). LPS regulate a differential expression of several Zn transporters (Ho et al., 2004) and Kitamura et al. (Kitamura et al., 2006) showed that the modulating $\mathrm{Zn}$ homeostasis has a profound impact on DCs, whereby available $\mathrm{Zn}$ diminishes DC activation. $\mathrm{Zn}$ acts on the level of phosphodiesterase (PDE) activity (von Bulow et al., 2005) and IL-1 receptor-associated kinaze (IRAK) phosphorylation (Wellinghausen et al., 1997), resulting in a decreased nuclear factor (NF)- $\mathrm{KB}$ activation and LPS-induced secretion of pro-inflammatory cytokines (Zhou et al., 2004). Because the LPS-stimulated up-regulation of MHC is known to be blocked by cyclic adenosine monophosphate (cAMP) (Kambayashi et al., 2001), a Zn-mediated rise in cyclic nucleotides could be the mechanism by which this metal down-regulated $\mathrm{MHC}$ expression in our experiments. In either case, the mechanisms for the observed effects of Ni-Ti RS ribbons probably include complex synergistic effects of the surface's microstructure and $\mathrm{Ni}$, Ti and $\mathrm{Zn}$ ions in a dynamic cell culture condition. However, this hypothesis needs to be tested further.

\section{Conclusion}

In this study we showed that the melt-spinning technique can be a new approach for the production of Ni-Ti SMAs, which further form a thin homogenous $\mathrm{TiO}_{2}$ surface layer that improves significantly the biocompatibility of Ni-Ti ribbons. However, we showed that the ribbons enhanced the tolerogenic properties of immature MoDCs in vitro by stimulating IL-10 and TGF- $\beta$ production by $\mathrm{CD}^{+} \mathrm{T}$ cells. In the presence of LPS, on the other hand, Ni-Ti RS ribbons enhance the Th1 polarising capacity of MoDCs, while inhibiting Th17 and Th2 differentiation. Based on these findings, we conclude that Ni-Ti RS ribbons, used for example as stents to threat occlusive vascular diseases, could potentially induce desired tolerogenic effects upon implantation. However, in the case of infection or inflammation, at least those mediated by LPS, care should be taken as to whether Ni-Ti RS ribbons will induce a desired or adverse effect. Namely, in conditions with the pathological Th17- or Th2-mediated inflammation, the implantation of Ni-Ti RS ribbons could be beneficial. On the other hand, in the Th1 dominant immunopathology, implanted Ni-Ti ribbons could aggravate the inflammatory process. However, to prove this hypothesis, extensive in vivo studies on different animal models should be conducted, even though human and animal DCs differ in many aspects of their phenotype and functions.

\section{Acknowledgments}

This study was supported by the EUREKA Project E!3971 BIO-SMA and the Project of the Ministry of Science 
and Technological Development of Serbia (Project no. 175102). The authors thank the University of Belgrade, High School of Dentistry (D. Stamenković, V. Lazić), University of Leoben, Department of Physical Metallurgy and Materials Testing (A.C. Kneissl, K. Mehrabi), Institute of Metals and Materials Ljubljana (M. Jenko, M. Pečar), the firm Zlatarna Celje d.d., an EUREKA Project E!3971 BIO-SMA collaborator, and other collaborators from Military Medical Academy, Belgrade (T. Džopalić, A. Dragićević, J. Đokić, I. Rajković, S. Vasilijić) and Faculty of Mechanical Engineering, Maribor (L. Zorko) for their helpful assistance during the experiments.

\section{References}

Aggarwal S, Ghilardi N, Xie MH, de Sauvage FJ, Gurney AL (2003) Interleukin-23 promotes a distinct CD4 $\mathrm{T}$ cell activation state characterized by the production of interleukin-17. J Biol Chem 278: 1910-1914.

Aiba S, Manome H, Nakagawa S, Mollah ZU, Mizuashi M, Ohtani T, Yoshino Y, Tagami H (2003) p38 Mitogen-activated protein kinase and extracellular signalregulated kinases play distinct roles in the activation of dendritic cells by two representative haptens, $\mathrm{NiCl} 2$ and 2,4-dinitrochlorobenzene. J Invest Dermatol 120: 390-399.

Anzel I, Kneissl AC, Rudolf R, Krizman A (2009) Wärmebeständigkeit einer rasch erstarrten $\mathrm{Cu}-\mathrm{Zr}$ Legierung / Thermal stability of a rapidly solidified $\mathrm{Cu}-\mathrm{Zr}$ alloys. Prakt Metallogr 46: 657-670.

Banchereau J, Briere F, Caux C, Davoust J, Lebecque S, Liu YJ, Pulendran B, Palucka K (2000) Immunobiology of dendritic cells. Annu Rev Immunol 18: 767-811.

Bannai S (1992) Use of 2-mercaptoethanol in cell culture. Hum Cell 5: 292-297.

Bender A, Sapp M, Schuler G, Steinman RM, Bhardwaj N (1996) Improved methods for the generation of dendritic cells from nonproliferating progenitors in human blood. J Immunol Methods 196: 121-135.

Bogdanski D, Esenwein SA, Prymak O, Epple M, Muhr G, Koller M (2004) Inhibition of PMN apoptosis after adherence to dip-coated calcium phosphate surfaces on a NiTi shape memory alloy. Biomaterials 25: 4627-4632.

Buehler W, Wang F (1968) A summary of recent research on nitinol alloys and their potential application in ocean engineering. Ocean Eng 1: 105-120.

Chan EP, Mhawi A, Clode P, Saunders M, Filgueira L (2009) Effects of titanium(iv) ions on human monocytederived dendritic cells. Metallomics 1: 166-174.

Chu C, Wang R, Hu T, Yin L, Pu Y, Lin P, Dong Y, Guo C, Chung C, Yeung K, Chu P (2009) XPS and biocompatibility studies of titania film on anodized NiTi shape memory alloy. J MaterSci: Mater Med 20: 223-228.

Colic M, Rudolf R, Stamenkovic D, Anzel I, Vucevic D, Jenko M, Lazic V, Lojen G (2010) Relationship between microstructure, cytotoxicity and corrosion properties of a Cu-Al-Ni shape memory alloy. Acta Biomater 6: 308-317.

Colic M, Stojic-Vukanic Z, Pavlovic B, Jandric D, Stefanoska I (2003) Mycophenolate mofetil inhibits differentiation, maturation and allostimulatory function of human monocyte-derived dendritic cells. Clin Exp Immunol 134: 63-69.

Constant SL, Bottomly K (1997) Induction of Th1 and Th2 CD4+ T cell responses: the alternative approaches. Annu Rev Immunol 15: 297-322.

Cucak H, Yrlid U, Reizis B, Kalinke U, JohanssonLindbom B (2009) Type I interferon signaling in dendritic cells stimulates the development of lymph-node-resident $\mathrm{T}$ follicular helper cells. Immunity 31: 491-501.

Das KK, Das SN, Dhundasi SA (2008) Nickel, its adverse health effects \& oxidative stress. Indian J Med Res 128: 412-425.

Es-Souni M, Fischer-Brandies H (2005) Assessing the biocompatibility of NiTi shape memory alloys used for medical applications. Anal Bioanal Chem 381: 557-567.

Es-Souni M, Fischer-Brandies H (2007) Human gingival fibroblast response to electropolished NiTi surfaces. J Biomed Mater Res A 80: 159-166.

Fischer AB (1975) Gentamicin as a bactericidal antibiotic in tissue culture. Med Microbiol Immun 161: 23-39.

Fisher PJ, Bulur PA, Vuk-Pavlovic S, Prendergast FG, Dietz AB (2008) Dendritic cell microvilli: a novel membrane structure associated with the multifocal synapse and T-cell clustering. Blood 112: 5037-5045.

Gunaratnam M, Grant MH (2004) Damage to F-actin and cell death induced by chromium VI and nickel in primary monolayer cultures of rat hepatocytes. Toxicol In Vitro 18: 245-253.

Hasany SM, Chughtai FA, Ghaffar A (1991) Sorption behavior of microamounts of zinc on titanium oxide from aqueous solutions. Separation Science and Technology 26: 1131 - 1146.

Ho LH, Ruffin RE, Murgia C, Li L, Krilis SA, Zalewski PD (2004) Labile zinc and zinc transporter ZnT4 in mast cell granules: role in regulation of caspase activation and NF-kappaB translocation. J Immunol 172: 7750-7760.

Hoh DJ, Hoh BL, Amar AP, Wang MY (2009) Shape memory alloys: metallurgy, biocompatibility, and biomechanics for neurosurgical applications. Neurosurgery 64: 199-214; discussion 214-195.

Hu J, Wan Y (2011) Tolerogenic dendritic cells and their potential applications. Immunology 132: 307-314.

$\mathrm{Hu}$ X, Paik PK, Chen J, Yarilina A, Kockeritz L, Lu TT, Woodgett JR, Ivashkiv LB (2006) IFN-gamma suppresses IL-10 production and synergizes with TLR 2 by regulating GSK3 and CREB/AP-1 proteins. Immunity 24: 563-574.

Hunter CA (2005) New IL-12-family members: IL-23 and IL-27, cytokines with divergent functions. Nat Rev Immunol 5: 521-531.

Inaba K, Witmer-Pack M, Inaba M, Hathcock KS, Sakuta H, Azuma M, Yagita H, Okumura K, Linsley PS, Ikehara S, Muramatsu S, Hodes RJ, Steinman RM (1994) The tissue distribution of the B7-2 costimulator in mice: abundant expression on dendritic cells in situ and during maturation in vitro. J Exp Med 180: 1849-1860.

Inaba K, Turley S, Iyoda T, Yamaide F, Shimoyama S, Reis e Sousa C, Germain RN, Mellman I, Steinman RM (2000) The formation of immunogenic major histocompatibility complex class II-peptide ligands in lysosomal compartments of dendritic cells is regulated by inflammatory stimuli. J Exp Med 191: 927-936. 
Inernational Standards Organisation (2009) Dentistry - preclinical evaluation of biocompatibility of medical devices used in dentistry - test methods for dental materials. ISO 10993-5: 2009 (E). Geneva.

Kaiko GE, Horvat JC, Beagley KW, Hansbro PM (2008) Immunological decision-making: how does the immune system decide to mount a helper T-cell response? Immunology 123: 326-338.

Kambayashi T, Wallin RP, Ljunggren HG (2001) cAMP-elevating agents suppress dendritic cell function. J Leukoc Biol 70: 903-910.

Kawai T, Akira S (2010) The role of pattern-recognition receptors in innate immunity: update on Toll-like receptors. Nat Immunol 11: 373-384.

Kishimoto T (2010) IL-6: from its discovery to clinical applications. Int Immunol 22: 347-352.

Kitamura H, Morikawa H, Kamon H, Iguchi M, Hojyo S, Fukada T, Yamashita S, Kaisho T, Akira S, Murakami M, Hirano T (2006) Toll-like receptor-mediated regulation of zinc homeostasis influences dendritic cell function. Nat Immunol 7: 971-977.

Klein CB, Frenkel K, Costa M (1991) The role of oxidative processes in metal carcinogenesis. Chem Res Toxicol 4: 592-604.

Kneissl AC, Unterweger E, Lojen G (2006) Functional Properties of Wires and Thin Ribbons of Several Shape Memory Alloys. Advanced Engineering Materials 8: 1113 1118.

Korn T, Bettelli E, Oukka M, and Kuchroo VK (2009) IL17 and Th17 Cells. Ann Rev Immun 27: 485-517.

Kramer MJ, Mecco H, Dennis KW, Vargonova E, McCallum RW, Napolitano RE (2007) Rapid solidification and metallic glass formation - Experimental and theoretical limits. J. Non-Cryst. Solids 353: 3633-3639.

Leist M, Single B, Castoldi AF, Kuhnle S, Nicotera P (1997) Intracellular adenosine triphosphate (ATP) concentration: a switch in the decision between apoptosis and necrosis. J Exp Med 185: 1481-1486.

Lifeng Z, Yan H, Dayun Y, Xiaoying L, Tingfei X, Deyuan Z, Ying H, Jinfeng Y (2011) The underlying biological mechanisms of biocompatibility differences between bare and TiN-coated NiTi alloys. Biomed Mater 6: 025012 .

Lin ZQ, Kondo T, Ishida Y, Takayasu T, Mukaida N (2003) Essential involvement of IL-6 in the skin woundhealing process as evidenced by delayed wound healing in IL-6-deficient mice. J Leukoc Biol 73: 713-721.

Lojen G, Anzel I, Kneissl A, Unterweger E, Kosec B, Bizjak M (2005) Microstructure of rapidly solidified CuAl-Ni shape memory alloy ribbons. J Mat Proc Tech 162: 220-229.

Lu X, Bao X, Huang Y, Qu Y, Lu H, Lu Z (2009) Mechanisms of cytotoxicity of nickel ions based on gene expression profiles. Biomaterials 30: 141-148.

Lutz MB, Schuler G (2002) Immature, semi-mature and fully mature dendritic cells: which signals induce tolerance or immunity? Trends Immunol 23: 445-449.

Magram J, Connaughton SE, Warrier RR, Carvajal DM, Wu CY, Ferrante J, Stewart C, Sarmiento U, Faherty DA, Gately MK (1996) IL-12-deficient mice are defective in IFN gamma production and type 1 cytokine responses. Immunity 4: 471-481.

McAleer JP, Liu B, Li Z, Ngoi SM, Dai J, Oft M, Vella AT (2010) Potent intestinal Th17 priming through peripheral lipopolysaccharide-based immunization. J Leukoc Biol 88: 21-31.

McGeachy MJ, Cua DJ (2008) Th17 cell differentiation: the long and winding road. Immunity 28: 445-453.

McNab FW, Rajsbaum R, Stoye JP, O'Garra A (2011) Tripartite-motif proteins and innate immune regulation. Curr Opin Immunol 23: 46-56.

Mehrabi K, Bruncko M, McKay BJ, Kneissl AC (2009) Influence of quenching rates on equiatomic NiTi ribbons fabricated by melt-spinning. J Mater Eng Perform 18: 475-478.

Messer HH, Murray EJ, Goebel NK (1982) Removal of trace metals from culture media and sera for in vitro deficiency studies. J Nutr 112: 652-657.

Messer RL, Tackas G, Mickalonis J, Brown Y, Lewis JB, Wataha JC (2009) Corrosion of machined titanium dental implants under inflammatory conditions. J Biomed Mater Res B Appl Biomater 88: 474-481.

Moulon C, Vollmer J, Weltzien HU (1995) Characterization of processing requirements and metal cross-reactivities in T cell clones from patients with allergic contact dermatitis to nickel. Eur J Immunol 25: 3308-3315.

Peitsch T, Klocke A, Kahl-Nieke B, Prymak O, Epple M (2007) The release of nickel from orthodontic NiTi wires is increased by dynamic mechanical loading but not constrained by surface nitridation. J Biomed Mater Res A 82: 731-739.

Rink L, Haase H (2007) Zinc homeostasis and immunity. Trends Immunol 28: 1-4.

Rogers TH, Babensee JE (2011) The role of integrins in the recognition and response of dendritic cells to biomaterials. Biomaterials 32: 1270-1279.

Rudolf R, Mehrabi K, Kneissl AC, Bruncko M, Anzel I, Tomic S, Dzopalic T, Colic M (2010) The response of peripheral blood mononuclear cells to shape memory alloys. International Journal of Immunological Studies 1: 214 - 228.

Sallusto F, Lanzavecchia A(1994) Efficient presentation of soluble antigen by cultured human dendritic cells is maintained by granulocyte/macrophage colony-stimulating factor plus interleukin 4 and downregulated by tumor necrosis factor alpha. J Exp Med 179: 1109-1118.

Santamarta R, Cesari E, Pons J, Goryczka T (2004) Shape memory properties of Ni-Ti based melt-spun ribbons. Metall Mater Trans A 35: 761-770.

Saraiva M, O'Garra A (2010) The regulation of IL-10 production by immune cells. Nat Rev Immunol 10: 170181.

Shabalovskaya SA (1996) On the nature of the biocompatibility and on medical applications of NiTi shape memory and superelastic alloys. Biomed Mater Eng 6: 267-289.

Shabalovskaya SA (2002) Surface, corrosion and biocompatibility aspects of Nitinol as an implant material. Biomed Mater Eng 12: 69-109.

Shabalovskaya SA, Anderegg JW (1995) Surface spectroscopic characterization of TiNi nearly equiatomic 
shape memory alloys for implants. J Vac Sci Technol A 13: $2624-2633$

Shabalovskaya S, Anderegg J, Van Humbeeck J (2008) Critical overview of Nitinol surfaces and their modifications for medical applications. Acta Biomater 4: 447-467.

Steinman RM, Witmer-Pack M, Inaba K (1993) Dendritic cells: antigen presentation, accessory function and clinical relevance. Adv Exp Med Biol 329: 1-9.

Steinman RM, Hawiger D, Nussenzweig MC (2003) Tolerogenic dendritic cells. Annu Rev Immunol 21: 685711.

Sun T, Wang LP, Wang M (2011) (Ti, O)/Ti and (Ti, $\mathrm{O}, \mathrm{N}) / \mathrm{Ti}$ composite coatings fabricated via PIIID for the medical application of NiTi shape memory alloy. J Biomed Mater Res B Appl Biomater 96: 249-260.

Sun T, Wang M (2010) A comparative study on titania layers formed on Ti, Ti-6Al-4V and NiTi shape memory alloy through a low temperature oxidation process. Surf Coat Technol 205: 92-101.

Trepanier C, Tabrizian M, Yahia LH, Bilodeau L, Piron DL (1998) Effect of modification of oxide layer on NiTi stent corrosion resistance. J Biomed Mater Res 43: 433440 .

Trinchieri G (2003) Interleukin-12 and the regulation of innate resistance and adaptive immunity. Nat Rev Immunol 3: 133-146.

Tze LE, Horikawa K, Domaschenz H, Howard DR, Roots CM, Rigby RJ, Way DA, Ohmura-Hoshino M, Ishido S, Andoniou CE, Degli-Esposti MA, Goodnow CC (2011) CD83 increases MHC II and CD86 on dendritic cells by opposing IL-10-driven MARCH1-mediated ubiquitination and degradation. J Exp Med 208: 149-165.

Unterweger E, Lojen G, Kneissl AC, Anzel I (2005) Dünne Bänder aus CuAlNi-Formgedächtnislegierungen hergesellt durch Melt-Spinning / Thin ribbons of CuAlNi shape memory alloys manufactured by melt-spinning. Prakt Metallogr 42: 435-444.

Vignali DA, Collison LW, Workman CJ (2008) How regulatory T cells work. Nat Rev Immunol 8: 523-532.

von Bulow V, Rink L, Haase H (2005) Zinc-mediated inhibition of cyclic nucleotide phosphodiesterase activity and expression suppresses TNF-alpha and IL-1 beta production in monocytes by elevation of guanosine 3',5'-cyclic monophosphate. J Immunol 175: 4697-4705.

Wellinghausen N, Martin M, Rink L (1997) Zinc inhibits interleukin-1-dependent T cell stimulation. Eur J Immunol 27: 2529-2535.

Wever DJ, Veldhuizen AG, de Vries J, Busscher HJ, Uges DR, van Horn JR (1998) Electrochemical and surface characterization of a nickel-titanium alloy. Biomaterials 19: 761-769.

Williams D, Williams R (1996)Degradative effects of the biological environment on metals and ceramics. In: Biomaterials science; an introduction to materials in medicine (B. Ratner, A. Hoffman, F. Schoen, J. Lemons, eds), Academic Press, San Diego, pp 260-267.

Yoshimura T, Takeda A, Hamano S, Miyazaki Y, Kinjyo I, Ishibashi T, Yoshimura A, Yoshida H (2006) Two-sided roles of IL-27: induction of Th1 differentiation on naive CD4+ T cells versus suppression of pro-inflammatory cytokine production including IL-23-induced IL-17 on activated CD4+ T cells partially through STAT3-dependent mechanism. J Immunol 177: 5377-5385.

Zhou Z, Wang L, Song Z, Saari JT, McClain CJ, Kang YJ (2004) Abrogation of nuclear factor-kappaB activation is involved in zinc inhibition of lipopolysaccharide-induced tumor necrosis factor-alpha production and liver injury. Am J Pathol 164: 1547-1556.

\section{Discussion with Reviewers}

Reviewer II: What could be the possible clinical applications of Rapid Solidified Ni-Ti Shape Memory Alloy, in relation to effects on dendritic cells and the immune system?

Authors: Ni-Ti alloys have revolutionised the field of metallic biomaterials since they improve significantly the quality of diagnostics, treatments and surgeries (Li et al., 2010, additional reference). Ni-Ti stents or stent/grafts are already in use for the treatment of vascular aneurysms or vascular occlusive diseases caused by atherosclerosis (Duerig et al., 2000, additional reference). The treatment exploits the ability of Ni-Ti stents to recover their trained shape, thus allowing the expansion of stenotic blood vessels or bypassing the dilated vessel wall of an aneurysm. Studies involving coronary self-expanding stents in animals and humans (Kobayashi et al., 2001; Roguin et al., 1999, additional references) have concluded that $\mathrm{Ni}-\mathrm{Ti}$ stents expand continuously after placement. The process is important for the prevention of restenosis. Thin Ni-Ti alloys were shown to fit much better for such use, especially if the blood vessels are smaller in diameter (Chun et al., 2009, additional reference). We think that Ni-Ti RS ribbons could meet the requirements for this type of stents.

The mechanisms involved in the development and progression of both aneurisms and atherosclerosis involve the immune system components, including Dendritic Cells (DC) (Sharma and Li, 2006; Jagadesham et al., 2008, additional references). DCs in the atherosclerotic plaque and aneurismal wall originate from blood DCs precursors, including monocytes, which transform into vascular DCs upon their transmigration (Banchereau et al., 2000 , text reference). The immunology of these vascular diseases is complex and not well understood. Although contradictory results have been published regarding the role of Th subsets in the pathogenesis of atherosclerosis and aneurism development, it seems that the Th1 subset is more important for the progression of atherosclerosis, whereas the immunopathology of aneurism progression is mediated by Th2 cells (Libby et al., 2009; Schonbeck et al., 2002; Xiong et al., 2004, additional references). In contrast, the role of Th17 cells is just starting to emerge. Recently, Madhur et al. (2010, additional reference) showed in a mouse model that IL-17 could promote atherosclerosis, but protect against aneurismal rupture.

A pro-tolerogenic environment could be beneficial for both diseases and various therapies are aimed to improve such tolerogenicity. Therefore, the tolerogenic properties of Ni-Ti RS ribbons under physiological conditions could be beneficial in preventing the disease progression. However, 
their application could be questionable if the diseases are accompanied by extensive inflammatory reactions. Namely, we provided evidence that MoDCs upon contact with Ni-Ti RS ribbons under inflammatory conditions stimulated Th1 and down-regulated Th2 and Th17 responses. Therefore, Ni-Ti RS ribbons could aggravate the diseases mediated by pathologic Th responses. However, if the pathology is mediated by Th17 or Th2 cytokines, the ribbons, in addition to their mechanical repair properties, could exert anti-inflammatory effects.

Another possible state-of-the-art application of Ni-Ti RS ribbons could be in a promising new field of microactuators and micro-electro-mechanical systems. The thinner the SMA is, the smaller is the amount of thermal mass needed to heat or cool it, which means a lesser time for the response and the increased speed for a designed operation to occur. Besides the good mechanical properties of Ni-Ti RS ribbons required for such application, and which we have described recently (Mehabri et al, 2011, in the press), their tolerogenicity could be advantageous if the devices are designed for implantation.

Reviewer II: May the reduction of the nickel release from $\mathrm{Ni}$-Ti RS ribbons and the enhancement of the tolerogenic properties of MoDC reduce the occurrence of sensitisation? Authors: Hapten-mediated contact sensitisation results from the binding of small molecules, in this case Ni ions, to larger proteins, thereby converting self-antigens to highly immunogenic 'foreign' peptides when presented in the context of MHC molecules by DCs (Roediger and Weninger, 2011, additional reference). Ni-protein complexes were shown to up-regulate the expression of CD83, co-stimulatory molecules (CD80, CD86 and CD40) and the chemokine receptor CCR7 (Arrighi et al., 2001, additional reference). However, it was not known until recently why Ni-protein activates human DCs, but cannot induce mice DC sensitisation to nickel without an additional adjuvant (Artik et al., 1999, additional reference). Schmidt et al. (2010, additional reference) showed recently that the human, but not mouse, Toll like receptor 4 (TLR4) can recognise Ni-protein complexes. However, it is not clear why only some individuals are prone to Ni-sensitisation. The serious adverse effects, including thrombosis, inflammation and even sudden death (Das et al., 2008, text reference) in some patients with implanted Ni-Ti based alloy devices could be explained by their hypersensitivity to $\mathrm{Ni}$. The decrease of $\mathrm{Ni}$ ion release from $\mathrm{Ni}$-Ti SMAs may reduce the occurrence of $\mathrm{Ni}-\mathrm{Ti}$ sensitisation. In this context, Ni-Ti RS ribbons showing negligible Ni release, together with the stimulation of tolerogenicity of DCs, could be desirable for implantation. However, it remains to be studied whether DCs from persons susceptible to $\mathrm{Ni}$-Ti sensitisation respond to $\mathrm{Ni}-\mathrm{Ti}$ RS ribbons in a similar manner.

Reviewer III: The authors mention in the discussion that the oxygen layer increase in thickness in the culture medium, did the authors look at the kinetics of this process? Will this continue with time or does this slow down resulting in passivation of the surface?
Authors: Prior to conditioning in cell culture medium, the thickness of the oxygen layer of Ni-Ti RS ribbons was estimated to be around $12 \mathrm{~nm}$, mostly consisting of $\mathrm{TiO}_{2}$. After two days of the conditioning it increased to around 15 $\mathrm{nm}$. These results are consistent with our previous finding on $\mathrm{Cu}-\mathrm{Al}-\mathrm{Ni} \mathrm{RS}$ ribbons (Colic et al., 2010, text reference) showing that the conditioning of $\mathrm{Cu}-\mathrm{Al}-\mathrm{Ni}$ alloys in cell culture media can enhance their biocompatibility, reducing the release of potentially toxic ions due to thickening of the oxide layer. The studies performed by Kimura and Sohmura (1987, additional reference) and Trepanier et al. (1998, text reference), concerning the growth of an oxide layer on NiTi alloys in physiological solutions, are also in line with our results.

The kinetics of the growth of the oxygen layer on $\mathrm{Ni}-\mathrm{Ti}$ alloys depend greatly on the microstructure of the alloy, temperature and surrounding environment. The growth of the oxide layers follows a model of oxygen absorption on the Ni-Ti surface that reacts with outward diffusing $\mathrm{Ti}^{+}$ to form $\mathrm{TiO}_{2}$ (Trepanier et al., 2000, additional reference). During the early stages of oxidation the growth of $\mathrm{TiO}_{2}$ is the primary contributor to thickness and therefore the oxide formation is relatively rapid. However, the preferential oxidation of $\mathrm{Ti}$ creates a Ni-rich zone at the $\mathrm{Ti}-\mathrm{Ni} / \mathrm{TiO}_{2}$ interface. The formation of the $\mathrm{Ni}_{3} \mathrm{Ti}$ layer increases the effective diffusion distance with an associated decrease in overall oxidation kinetics. Biological fluids, on the other hand, are strong corrosive environments where $\mathrm{Cl}^{-}$ions can cause pitting corrosion on the surface of Ni-Ti implants (Pourbaix, 1984, additional reference). The early process of corrosion takes place on the surface defects and on thin oxide layers, which leads to Ni release. The remaining Ti reacts with dissolved oxygen in the solution to form Tioxides around the pitting sites and pores leading to oxide layer growth and propagation over the entire surface of the Ni-Ti specimen. The thickness of the oxygen layer does not increase linearly with time, but it decreases as corrosion proceeds, indicating that the as-formed Ti oxide layer may impede further corrosion of the Ni-Ti SMAs in the $\mathrm{NaCl}$ solution (Hu et al., 2010, additional reference).

However, to our knowledge, there is no direct evaluation of the kinetics of the Ti-oxygen layer growth in cell culture media and the process has not been evaluated in this study. Based on the published corrosion studies and the oxide layer growth on $\mathrm{Ni}$ - $\mathrm{Ti}$ alloys in $\mathrm{NaCl}$ solution we would expect lower kinetics of the oxygen growth on $\mathrm{Ni}-\mathrm{Ti} \mathrm{RS}$ ribbons due to the presence of serum proteins in the medium. At the same time, the proteins could protect the surface of the Ni-Ti RS ribbons from a direct attack by $\mathrm{Cl}^{-}$ions. Therefore, this problem deserves to be investigated thoroughly in further experiments.

Reviewer III: How well does the oxygen / oxide layer respond to loading, is it mechanically stable?

Authors: This is probably the most important question needing to be addressed prior to the potential use of $\mathrm{Ni}$-Ti RS ribbons as stents or other kinds of implants. In contrast to static conditions, where the protective $\mathrm{TiO}_{2}$ layer prevents leaching of $\mathrm{Ni}$ ions, the cyclic deformation may result in failure of the protective oxide layer. Therefore, 
it should be emphasised that the ceramic nature of $\mathrm{TiO}_{2}$ contradicts both $\mathrm{Ni}-\mathrm{Ti}$ superelasticity and the cyclic pulsation of blood vessels (Shabalovskaya et al., 2009, additional reference). Oxide layers are brittle and crack under tensile stress. In addition, the thicker the layers, the higher the tendency for crack formation. The reason for this is because ceramic materials are held together by ionic and covalent bonds, which tend to fracture before any plastic deformation (Shabalovskaya et al., 2009, additional reference).

Several papers reported that pseudoelastic Ni-Ti SMA samples deformed 0.6-3\%, strain developed cracks in the relatively thick protective $\mathrm{TiO}_{2}$ layer and exposed Nirich phases leading to increased $\mathrm{Ni}$ ion release (Undisz et al., 2009; Zhu et al., 2004, additional references). On the other hand, as shown by Kimura and Sohmura (1987, additional reference), a thin oxide layer is preferable to maintain the integrity of the surface layer to sustain the large deformation induced by the shape memory effect. Habijan et al. (2011, additional reference) recently showed that Ni-Ti with an electro-polished surface which contains a dense and several nm thick oxide layer, released a small amount of $\mathrm{Ni}$ (up to $25 \mathrm{ppm}$ ) either in static or in mechanical loading conditions, even after 7 days of the conditioning. This finding suggests that small mechanical strains have no additional effect of the Ni release. The authors suggested that since the Ti-oxide layer is very brittle, it is more likely that the self-healing processes reestablish the Ti-oxide layer in biological medium during the mechanical cycling. In line with this finding, one can expect similar behaviour of our Ni-Ti RS ribbons, since during conditioning the Ti-oxide layer was still thin.

Reviewer IV: I am not an expert in metallurgy, but as someone who uses these devices for primary cell cultures, I found this article to be very interesting. It enables one to understand the complicating immune responses and limitations of the current technology in developing alloy metals. However, for clinical applications, their safety in the complex body system should be proven by further in vivo experiments, because any procedure or operation itself for the implantation of new materials could be inflammatory.

Authors: In vitro cytocompatibility studies are a prerequisite for any material intended to be implanted in the body (Richards et al., 2001, additional reference). However, cytocompatible materials which passed additional biocompatible studies in vivo could have some adverse chronic reactions, mostly related to the activation of the immune system. Our complex cytocompatibility and immunobiology studies on DCs, as key initiators and regulators of the immune response, suggest that cytocompatible Ni-Ti RS ribbons might have some beneficial, but also may provoke some unwanted effects if applied as biomaterials. The using of Ni-Ti RS ribbons as potential stents to treat vascular occlusive diseases could be advantageous if the stents shift the immune response toward increased tolerogenicity. Usually, DCs or their precursors transmigrated from the blood through the vascular wall are in the immature state and posses tolerogenic properties (Galkina and Ley, 2009, additional reference; Steinman et al., 2003, text reference). Therefore, the contact of such DCs with Ni-Ti RS ribbons (used as stents) could make these cells even more tolerogenic. Even though Ni-Ti RS ribbons-experienced DCs subsequently encounter the pro-inflammatory cytokines milieu within the atherosclerotic lesion, these cells could still retain their tolerogenic potential. Namely, it has been shown that additional factors in atherosclerotic lesion, such as oxidised phospholipids (a well known pro-atherogenic factor), prevent maturation and immunostimulatory capability of DCs (Bluml et al., 2005, additional reference). On the other hand, during infection/inflammation, Ni-Ti RS ribbons (used as any bioimplant) could activate local DCs leading to exacerbation and perpetuation of inflammatory responses with possible negative consequences related to implant rejection.

Therefore, to make an appropriate conclusion about the safety of Ni-Ti RS ribbons as bioimplants, a number of additional studies are necessary. The studies should at first be designed on animals. In recent years, the development of inbred and transgenic strains of mice and rabbits has provided insights into the genetic and immunological basis of many diseases (Hoeg et al., 1996; Libby et al., 2011; Paigen et al., 1990, additional references). However, atherosclerosis, including the development of aneurisms, as a disease treated with stents, is not a natural disease in rodents and has to be induced dietarily, or in some other way. Therefore, although animal experiments have proven indispensable to studies of the mechanisms of vascular diseases, many limitations have to be considered thoroughly. Due to the difficult access to coronary, carotid and cerebral arteries, which are most important clinical consequences of vascular occlusive diseases in humans, mice studies focus generally on the aorta and proximal great vessels. The structure and hydrodynamics of these smaller muscular arteries, and even the embryonic origin of their smooth muscle cells, differ markedly from the large elastic arteries usually analysed in mouse studies (Libby et al., 2011; Narayanaswamy et al., 2000, additional references). In addition, the mouse immune system, although well understood and manipulated readily, diverges in many ways from that of humans. It is well known today that the subpopulations of resident and inflammatory dendritic cells (DCs), as well as other components of the immune system in mice, differ from that of humans, particularly in their phenotype and function (Shortman and Liu, 2002; Libby et al., 2011, additional references).

Therefore, except for the in vivo animal studies with implanted Ni-Ti RS ribbons, the comparative in vitro studies on mouse and human immune cells are necessary. Finally, if Ni-Ti RS ribbons fulfil all the criteria necessary for implantation, then long-term clinical studies would be necessary to check the immunological consequences of the biomaterial.

\section{Additional References}

Arrighi JF, Rebsamen M, Rousset F, Kindler V, Hauser C (2001) A critical role for $\mathrm{p} 38$ mitogen-activated protein kinase in the maturation of human blood-derived dendritic 
cells induced by lipopolysaccharide, TNF-alpha, and contact sensitizers. J Immunol 166: 3837-3845.

Artik S, von Vultee C, Gleichmann E, Schwarz T, Griem P (1999) Nickel allergy in mice: enhanced sensitization capacity of nickel at higher oxidation states. J Immunol 163: 1143-1152.

Bluml S, Kirchberger S, Bochkov VN, Kronke G, Stuhlmeier K, Majdic O, Zlabinger GJ, Knapp W, Binder BR, Stockl J, Leitinger N (2005) Oxidized phospholipids negatively regulate dendritic cell maturation induced by TLRs and CD40. J Immunol 175: 501-508.

Chun Y, Levi DS, Mohanchandra KP, Vinuela F, Fernando Vinuela J, Carman GP (2009) Superelastic NiTi thin film small vessel graft for vascular repair. Active and Passive Smart Structures and Integrated Systems Proceedings Vol. 7288.

Duerig TW, Tolomeo DE, Wholey M (2000) An overview of superelastic stent design. Minim Invasive Ther Allied Technol 9: 235-246.

Galkina E, Ley K (2009) Immune and Inflammatory mechanisms of atherosclerosis Annu Rev Immunol 27:165197

Habijan T, Glogowski T, Kuhn S, Pohl M, Wittsiepe J, Greulich C, Eggeler G, Schildhauer TA, Koller M (2011) Can human mesenchymal stem cells survive on a NiTi implant material subjected to cyclic loading? Acta Biomater 7: 2733-2739.

Hoeg JM, Santamarina-Fojo S, Berard AM, Cornhill JF, Herderick EE, Feldman SH, Haudenschild CC, Vaisman BL, Hoyt RF, Jr., Demosky SJ, Jr., Kauffman RD, Hazel CM, Marcovina SM, Brewer HB Jr. (1996) Overexpression of lecithin:cholesterol acyltransferase in transgenic rabbits prevents diet-induced atherosclerosis Proc Natl Acad Sci USA 93: 11448-11453.

$\mathrm{Hu}$ T, Chu C, Xin Y, Wu S, Yeung K, Chu P (2010) Corrosion products and mechanism on NiTi shape memory alloy in physiological environment. J Mat Res 25: 350-358.

Jagadesham VP, Scott DJ, Carding SR (2008) Abdominal aortic aneurysms: an autoimmune disease? Trends Mol Med 14: 522-529.

Kimura H, Sohmura T (1987) Surface coating on TiNi Shape memory implant alloys. J Osaka Univ Dent Sch 27: 211-223.

Kobayashi Y, Honda Y, Christie GL, Teirstein PS, Bailey SR, Brown CL, 3rd, Matthews RV, De Franco AC, Schwartz RS, Goldberg S, Popma JJ, Yock PG, Fitzgerald PJ (2001) Long-term vessel response to a self-expanding coronary stent: a serial volumetric intravascular ultrasound analysis from the ASSURE Trial.A Stent vs. Stent Ultrasound Remodeling Evaluation. J Am Coll Cardiol 37: 1329-1334.

Li Q, Zeng Y, Tang X (2010) The applications and research progresses of nickel-titanium shape memory alloy in reconstructive surgery. Australas Phys Eng Sci Med 33: 129-136.

Libby P, Ridker PM, Hansson GK (2009) Inflammation in atherosclerosis: from pathophysiology to practice. J Am Coll Cardiol 54: 2129-2138.
Libby P, Ridker PM, Hansson GK (2011) Progress and challenges in translating the biology of atherosclerosis Nature 473: 317-325.

Madhur MS, Lob HE, McCann LA, Iwakura Y, Blinder Y, Guzik TJ, Harrison DG (2010) Interleukin 17 promotes angiotensin II-induced hypertension and vascular dysfunction. Hypertension 55: 500-507.

Narayanaswamy M, Wright K C and Kandarpa K (2000) Animal models for atherosclerosis, restenosis, and endovascular graft research J Vasc Interv Radiol 11: 5-17

Paigen B, Ishida B Y, Verstuyft J, Winters R B and Albee D 1990 Atherosclerosis susceptibility differences among progenitors of recombinant inbred strains of mice Arteriosclerosis 10: 316-23

Pourbaix M (1984) Electrochemical corrosion of metallic biomaterials. Biomaterials 5: 122-134.

Richards RG, Stiffanic M, Owen GR, Riehle M, ap Gwynn I, Curtis AS (2001) Immunogold labelling of fibroblast focal adhesion sites visualised in fixed material using scanning electron microscopy, and living, using internal reflection microscopy. Cell Biol Int 25: 1237-1249.

Roediger B, Weninger W (2011) How nickel turns on innate immune cells. Immunol Cell Biol 89: 1-2.

Roguin A, Grenadier E, Linn S, Markiewicz W, Beyar $\mathrm{R}$ (1999) Continued expansion of the nitinol self-expanding coronary stent: angiographic analysis and 1-year clinical follow-up. Am Heart J 138: 326-333.

Schmidt M, Raghavan B, Muller V, Vogl T, Fejer G, Tchaptchet S, Keck S, Kalis C, Nielsen PJ, Galanos C, Roth J, Skerra A, Martin SF, Freudenberg MA, Goebeler M (2010) Crucial role for human Toll-like receptor 4 in the development of contact allergy to nickel. Nat Immunol 11: 814-819.

Schonbeck U, Sukhova GK, Gerdes N, Libby P (2002) $\mathrm{T}(\mathrm{H}) 2$ predominant immune responses prevail in human abdominal aortic aneurysm. Am J Pathol 161: 499-506.

Shabalovskaya SA, Tian H, Anderegg JW, Schryvers DU, Carroll WU, Van Humbeeck J (2009) The influence of surface oxides on the distribution and release of nickel from Nitinol wires. Biomaterials 30: 468-477.

Sharma R, Li DZ (2006) Role of dendritic cells in atherosclerosis. Asian Cardiovasc Thorac Ann 14: 166-169. Shortman K, Liu YJ (2002) Mouse and human dendritic cell subtypes Nat Rev Immunol 2: 151-61

Trepanier C, Venugopalan R, Pelton AR (2000) Corrosion resistance and biocompatibility of passivated nitinol. In: Shape Memory Implants (Yahia LH ed), Nitinol, pp 35-45.

Undisz A, Schrempel F, Wesch W, Rettenmayr M (2009) In situ observation of surface oxide layers on medical grade Ni-Ti alloy during straining. J Biomed Mater Res A 88: 1000-1009.

Xiong W, Zhao Y, Prall A, Greiner TC, Baxter BT (2004) Key roles of CD4+ T cells and IFN-gamma in the development of abdominal aortic aneurysms in a murine model. J Immunol 172: 2607-2612.

Zhu L, Trépanier C, Pelton AR, Fino J (2004) Oxidation of nitinol and its effect on corrosion resistance. Online 2009. Available from:http://www.nitinol.info/ pdf_files/003.pdf. 